\title{
$\alpha 9$ Integrin Promotes Neurite Outgrowth on Tenascin-C and Enhances Sensory Axon Regeneration
}

\author{
Melissa R. Andrews, ${ }^{1 \star}$ Stefan Czvitkovich, ${ }^{1 \star}$ Elisa Dassie, ${ }^{1}$ Christina F. Vogelaar, ${ }^{1}$ Andreas Faissner, ${ }^{2}$ Bas Blits, ${ }^{3}$ \\ Fred H. Gage, ${ }^{4}$ Charles ffrench-Constant, ${ }^{1}$ and James W. Fawcett ${ }^{1}$ \\ ${ }^{1}$ Cambridge Centre for Brain Repair, Department of Clinical Neurosciences, University of Cambridge, Cambridge CB2 2PY, United Kingdom, ${ }^{2}$ Department \\ of Cell Morphology and Molecular Neurobiology, Faculty of Biology, Ruhr University Bochum, 44780 Bochum, Germany, ${ }^{3}$ Laboratory for \\ Neuroregeneration, Netherlands Institute for Neuroscience, Institute of the Royal Academy of Arts and Sciences, 1105 BA Amsterdam, The Netherlands, \\ and ${ }^{4}$ Laboratory of Genetics, The Salk Institute for Biological Studies, La Jolla, California 92037
}

\begin{abstract}
Damaged CNS axons are prevented from regenerating by an environment containing many inhibitory factors. They also lack an integrin that interacts with tenascin-C, the main extracellular matrix glycoprotein of the CNS, which is upregulated after injury. The $\alpha 9 \beta 1$ integrin heterodimer is a receptor for the nonalternatively spliced region of tenascin-C, but the $\alpha 9$ subunit is absent in adult neurons. In this study, we show that PC12 cells and adult rat dorsal root ganglion (DRG) neurons do not extend neurites on tenascin-C. However, after forced expression of $\alpha 9$ integrin, extensive neurite outgrowth from PC12 cells and adult rat DRG neurons occurs. Moreover, both DRG neurons and PC1 2 cells secrete tenascin-C, enabling $\alpha 9$-transfected cells to grow axons on tissue culture plastic. Using adeno-associated viruses to express $\alpha 9$ integrin in vivo in DRGs, we examined axonal regeneration after cervical dorsal rhizotomy or dorsal column crush in the adult rat. After rhizotomy, significantly more dorsal root axons regrew into the dorsal root entry zone at 6 weeks after injury in $\alpha 9$ integrinexpressing animals than in green fluorescent protein (GFP) controls. Similarly, after a dorsal column crush injury, there was significantly more axonal growth into the lesion site compared with GFP controls at 6 weeks after injury. Behavioral analysis after spinal cord injury revealed that both experimental and control groups had an increased withdrawal latency in response to mechanical stimulation when compared with sham controls; however, in response to heat stimulation, normal withdrawal latencies returned after $\alpha 9$ integrin treatment but remained elevated in control groups.
\end{abstract}

\section{Introduction}

Regeneration of axons in the damaged CNS fails because of multiple inhibitory molecules, a lack of growth-promoting factors, and an intrinsically poor axonal regenerative response. Several molecules are upregulated after injury, including chondroitin sulfate proteoglycans and tenascin-C (TN-C) (for review, see Fawcett and Asher, 1999). TN-C is an extracellular matrix glycoprotein that inhibits the growth of many axons but that supports the growth of axons with appropriate receptors including some integrins and F3/F11/contactin (Bartsch, 1996; Meiners et al., 1999; Joester and Faissner, 2001; Rigato et al., 2002). TN-C has been shown to be upregulated after dorsal root (Pindzola et al.,

\footnotetext{
Received Feb. 13, 2009; accepted March 9, 2009.

This work was supported by The Wellcome Trust, The Christopher and Dana Reeve Foundation, the Medical Research Council, The Henry Smith Charity, Action Medical Research, and NeuroNE European Network (sixth framework program). We acknowledge the Vector Core at The Salk Institute for assistance in the production of AAVs. We are grateful to Sunil Kappangatula for assistance with DRG explant cultures, to David Story and RongRong Zhao for technical support, and to Mariette Vogelezang for assistance with integrin constructs and helpful discussions. We also thank David Tumbarello for assistance, constructive advice, and critical reading of this manuscript.

*M.R.A. and S.C. contributed equally to this work.

Correspondence should be addressed to Prof. James W. Fawcett, Cambridge Centre for Brain Repair, Department of Clinical Neurosciences, University of Cambridge, Robinson Way, Cambridge CB2 2PY, UK. E-mail: jf108@cam.ac.uk.

C. ffrench-Constant's present address: University of Edinburgh, Medical Research Council Centre for Regenerative Medicine, Queen's Medical Research Institute, 47 Little France Crescent, Edinburgh EH16 4TJ, UK. DOI:10.1523/JNEUROSCI.0759-09.2009

Copyright $\odot 2009$ Society for Neuroscience $\quad 0270-6474 / 09 / 295546-12 \$ 15.00 / 0$
}

1993; Golding et al., 1999) and spinal cord injury (Zhang et al., 1997; Tang et al., 2003).

Integrins are heterodimeric transmembrane receptors consisting of an $\alpha$ and $\beta$ subunit that mediate cell adhesion, proliferation, and migration by binding to extracellular matrix proteins. They promote neurite outgrowth in embryonic (Lein et al., 1991; Neugebauer et al., 1991), postnatal (Tomaselli et al., 1993; Vogelezang et al., 2001), and adult neurons (Condic 2001; Gardiner et al., 2005), and are involved in peripheral nerve regeneration (Vogelezang et al., 2001; Gardiner et al., 2005, 2007). After development, some integrin receptors are downregulated, resulting in adult neurons that are unable to interact with certain matrix molecules, including TN-C (Jones, 1996; Pinkstaff et al., 1999), and cells may lose the ability to regulate surface integrin levels to optimize cell-matrix interactions. For example, embryonic neurons adapt to allow growth on inhibitory substrates such as aggrecan by increasing expression of distinct integrins (Condic et al., 1999), whereas adult neurons are unable to respond similarly (Condic, 2001). To obtain optimal regeneration from dorsal root ganglion (DRG) neurons on laminin and fibronectin, it was necessary to overexpress $\alpha 1$ and $\alpha 5$ integrin subunits, which combine with the pool of $\beta 1$ subunit to produce receptors for laminin and fibronectin, promoting axon growth (Condic 2001). In the damaged CNS, there is an upregulation of TN-C; however, TN-C binding integrins, particularly $\alpha 9 \beta 1$, are absent in the adult nervous system (Wang et al., 1995; Staniszewska et al., 
2008), which may contribute to the inability of neurons to grow through TN-C-rich areas.

The aim of this study was to examine the hypothesis that neuronal expression of a TN-C binding integrin would enhance the ability of axons to regenerate in the TN-C-rich environment of the damaged CNS. We selected $\alpha 9 \beta 1$ integrin for this purpose because it uniquely binds to the nonalternatively spliced fn 3 domain of TN-C (Yokosaki et al., 1994, 1998). We examined the role of $\alpha 9$ integrin in vitro and observed an enhancement of neurite outgrowth in both PC12 cells and adult DRG neurons on TN-C. Additionally, we studied $\alpha 9$ integrin in vivo using adenoassociated virus in adult rat DRG neurons and observed an increase in the number of axons growing into the dorsal root entry zone (DREZ) after rhizotomy and into a spinal cord lesion after a dorsal column crush injury.

\section{Materials and Methods}

\section{Integrin constructs and chimeras}

cDNAs encoding wild-type $\alpha 9$ integrin were obtained from Dean Sheppard (University of California, San Francisco, San Francisco, CA). $\alpha 4$ and $\alpha 5$ integrin constructs were produced as previously described (Vogelezang et al., 2001). Generation of human $\alpha 9$ integrin missing the cytoplasmic domain was constructed by introducing a HindIII restriction site 10 bp proximal to the ATG start codon of $\alpha 9$ and a stop codon 2 amino acids after the transmembrane domain followed by a NotI restriction site before the GFFKR motif deleted the $\alpha 9$ protein. The fragment was amplified by PCR using the following primers: 5'-GCG CGC AAG CTT (HindIII) AGC GGG CGC TAT GGG GAG-3' (sense); 5' -GCG CGA (NotI) GCG GCC GCT TAC ATC TTC CAG AGC AGC AC-3' (antisense). After PCR, a band of the expected size of $3 \mathrm{~kb}$ was cut out and digested with HindIII and NotI and cloned into a pcDNA3 expression vector containing a neomycin resistance gene and a cytomegalovirus (CMV) promoter. For cloning an $\alpha 5 / \alpha 9$ construct, the $\alpha 5$ extracellular domain was cut out of a preexisting plasmid (kindly provided by Dean Sheppard) by a SalIHindIII double digest obtaining a fragment of $3 \mathrm{~kb}$, which was inserted into an empty SalI-HindIII cleaved pBluescript II SK(+) (kindly provided by Bernhard Payer, University of Cambridge, Cambridge, UK). A HindIII site was created at the beginning of the $\alpha 9$ intracellular domain, changing the amino acid sequence from KMGFFKR to KLGFFKR, which is the sequence for the native human $\alpha 5$ protein. At the $3^{\prime}$ end of the $\alpha 9$ tail, a SalI site was attached. The fragment was amplified with the following primers: $5^{\prime}$-GCG CGC AAG CTT (HindIII) GGC TTC TTT CGC CGA AGG TAC-3' (sense); 5'-GCG CGC GTC GAC (SalI) GTG GAT CAG GTC ATG TGA CTG-3' (antisense). A 151 bp fragment was excised, phosphorylated with PNK (polynucleotide kinase), and inserted by blunt end ligation into the SmaI site of the pBluescript II SK(+). A HindIII-NotI digest released a 188 bp fragment which was cloned into the pBluescript vector containing the extracellular and transmembrane $\alpha 5$ domain, thus generating a chimeric $\alpha 5 / \alpha 9$ cDNA. The $\alpha 5 / \alpha 9$ was cut out with SalI and cloned into the XhoI site of the pcDNA3 multiple cloning site.

\section{Generation of viruses}

Retrovirus. The cloning of human versions of $\alpha 4, \alpha 5, \alpha 9, \alpha 9 / 4$, and $\alpha 9 / 5$ integrin into a retroviral PLIXN backbone (Stratagene/Agilent Technologies) containing a neomycin resistance gene was performed as previously described for $\alpha 4$ integrin (Vogelezang et al., 2001).

Lentivirus. Generation of self-inactivating lentiviral vectors with farnesylated green fluorescent protein (fGFP) or $\alpha 9$ integrin-IRES-fGFP driven from the human CMV promoter was performed using previously published methods (Naldini et al., 1996; Ruitenberg et al., 2002). Viral titer was determined on HEK293T cells.

Adeno-associated virus. Recombinant adeno-associated virus 2 (AAV2) carrying fGFP or human $\alpha 9$ integrin driven from the human CMV promoter was produced in HEK293T cells as previously described (Xiao et al., 1998). High-titer virus was produced in association with the Vector Core (The Salk Institute) and Virapur.
Culture of rat pheochromocytoma (PC12) cells

PC12 cells were grown in 10\% horse serum (Invitrogen), 5\% FCS, 1\% penicillin/streptomycin (p/s), and $2 \mathrm{~mm}$ glutamine in DMEM on $0.01 \%$ poly-D-lysine (PDL)-coated tissue culture flasks. For differentiation, cells were seeded onto $20 \mu \mathrm{g} / \mathrm{ml}$ collagen (Sigma-Aldrich)-coated tissue culture dishes and maintained with $1 \%$ insulin, threonine, selenite (ITS+) (Collaborative Research), 1\% p/s, 2 mm glutamine, 50 ng/ml NGF (Serotec) in DMEM (“differentiation medium”).

\section{Adult rat DRG cultures}

Explants. Adult male Sprague Dawley rats were killed, and DRGs were removed and plated onto $10 \mu \mathrm{g} / \mathrm{ml}$ laminin, TN-C, or on tissue culture plastic. Explants were grown for $72 \mathrm{~h}$ at $37^{\circ} \mathrm{C}$ in $1 \% \mathrm{ITS}+, 1 \% \mathrm{p} / \mathrm{s}, 2 \mathrm{~mm}$ glutamine, $10 \mathrm{ng} / \mathrm{ml} \mathrm{NGF}$, and $10 \mathrm{ng} / \mathrm{ml}$ neurotrophin-3 (NT-3) (Calbiochem/Merck) in DMEM. The longest neurite from at least 25 explants was measured and the average was plotted in a graph. The experiment was repeated in triplicate. Statistical analysis was performed using oneway ANOVA test followed by post hoc analysis using SigmaStat software.

Dissociated DRGs. Adult male Sprague Dawley rats or adult C57BL/6 mice were killed, and DRGs were removed. DRGs were dissociated with $0.1 \%$ collagenase in DMEM for $1 \mathrm{~h}$ at $37^{\circ} \mathrm{C}$. Digested DRGs were rinsed with DMEM and grown in DRG culture medium [ $100 \mu \mathrm{g} / \mathrm{ml}$ transferrin (Sigma-Aldrich), $0.3 \%$ BSA, 2\% FCS, $1 \%$ p/s, $60 \mathrm{ng} / \mathrm{ml}$ progesterone (Sigma-Aldrich), $16 \mu \mathrm{g} / \mathrm{ml}$ putrescine (Sigma-Aldrich), $0.16 \mu \mathrm{g} / \mathrm{ml}$ sodium selenite (Sigma-Aldrich), $10 \mu \mathrm{g} / \mathrm{ml}$ insulin (Sigma-Aldrich), 10 $\mathrm{ng} / \mathrm{ml} \mathrm{NGF}, 10 \mathrm{ng} / \mathrm{ml} \mathrm{NT-3}$ (Calbiochem) in Ham's F-12 media (Invitrogen)].

\section{Cell transduction using virus}

Retrovirus. Retroviral infections of PC12 cells were performed in the presence of polybrene $(4 \mu \mathrm{g} / \mathrm{ml})$ and performed overnight at $37^{\circ} \mathrm{C}$. The following day, the virus was removed and cells were refed with fresh medium containing G418 (1 mg/ml). Cells were maintained in selection media.

Adenovirus. Dissociated DRG neurons (see above) of one adult rat $\left(\sim 5 \times 10^{4}\right.$ cells) were seeded into PDL-coated dishes (NUNC; Thermo Fisher Scientific) obtaining 12,000-15,000 cells/well and were cultured overnight. Next day, 100 plaque-forming units/cell of lacZ, $\alpha 9 / \alpha 9, \alpha 9 /$ $\alpha 4$, or $\alpha 9 / \alpha 5$ containing adenovirus were added to neurons and incubated for $48 \mathrm{~h}$ at $37^{\circ} \mathrm{C}$. Neurons were chilled for $15 \mathrm{~min}$ on ice, washed with HBSS (without $\mathrm{Mg}^{2+}$ and $\mathrm{Ca}^{2+}$ ) (Invitrogen), and seeded out in culture medium on either $10 \mu \mathrm{g} / \mathrm{ml}$ laminin (Sigma-Aldrich), TN-C (mouse TN-C) (Faissner and Kruse, 1990), or tissue culture plastic. Neurons were cultured for $72 \mathrm{~h}$ before analysis.

Lentiviral transduction. Lentiviral transduction of dissociated DRGs was performed as described for adenovirus using lentivirus (LV)-fGFP (viral titer, $6 \times 10^{8} \mathrm{tu} / \mathrm{ml}$ ) or LV- $\alpha 9$-IRES-fGFP (viral titer, $1 \times 10^{8}$ $\mathrm{tu} / \mathrm{ml}$ ) with a multiplicity of infection of 100 in the presence of polybrene $(4 \mu \mathrm{g} / \mathrm{ml})$.

Neurite outgrowth assay with PC12 cells

On substrates. Tissue culture plastic chamber slides (eight-well; NUNC; Thermo Fisher Scientific) coated with $10 \mu \mathrm{g} / \mathrm{ml}$ laminin, TN-C, or PBS were used for outgrowth assays in which differentiated PC12 cells were seeded at a density of $1 \times 10^{4}$ cells/well and grown for 24 or $48 \mathrm{~h}$ in differentiation medium.

On cryosections. Brains from adult female Sprague Dawley rats (200250 g; Charles River Laboratories) were removed and frozen in ice-cold isopentane followed by liquid nitrogen. Brains were cut coronally into $20-\mu \mathrm{m}$-thick sections on a cryostat and mounted on PDL-coated glass coverslips. Differentiated PC12 cells prelabeled with Cell Tracker Green (Invitrogen) were plated onto sections at a density of $5 \times 10^{4}$ cells/section.

On nitrocellulose filters. Experiments were conducted in accordance with the United Kingdom Animals (Scientific Procedure) Act of 1986. Adult female Sprague Dawley rats (200-250 g) were anesthetized with halothane (1-2\%) and a mixture of 50\% nitrous oxide and 50\% oxygen. Using a stereotaxic frame, an incision was made along the midline of the scalp, and a unilateral drill line $2.5 \mu \mathrm{m}$ from the midline was made extending between bregma and lambda. A cut was made parallel to the 
midline, $3 \mathrm{~mm}$ deep to dura. UV light-sterilized nitrocellulose filters $(10 \times 3 \mathrm{~mm}$ and $8 \mu \mathrm{m}$ pore size) (McKeon et al., 1991) were implanted into the injury. Animals were killed $14 \mathrm{~d}$ after injury and filters were removed for freezing in ice-cold isopentane followed by liquid nitrogen. Implants were rinsed in $0.02 \%$ EDTA/HBSS and maintained in culture with $1 \%$ ITS $+, 1 \% \mathrm{p} / \mathrm{s}, 1 \%$ glutamine, $0.01 \%$ BSA (Sigma-Aldrich) in DMEM. Differentiated PC12 cells were plated onto implants at a density of $2 \times 10^{4}$ cells/section.

In some of the cases above, blocking antibodies against human $\alpha 9 \beta 1$ integrin (clone Y9A2; Abcam) were added to the culture media at $10 \mu \mathrm{g} / \mathrm{ml}$.

\section{Analysis of neurite outgrowth of PC12 cells}

Substrates. Twenty-four or $48 \mathrm{~h}$ after plating, cultures were fixed with $4 \%$ paraformaldehyde (PFA), and blocked with 3\% BSA in PBS. Cells were incubated with rabbit polyclonal anti-neurofilament antibody $(1 \mu \mathrm{g} /$ $\mathrm{ml})$. Cells were washed with $0.1 \%$ Tween 20 in PBS and incubated with goat anti-rabbit biotinylated antibody (GE Healthcare) followed by an incubation in Cy3-streptavidin (GE Healthcare) in PBS and Hoechst (Sigma-Aldrich). Coverslips were mounted with Fluorosave (Calbiochem).

Cryocultures. Twenty-four hours after cell plating, cultures were fixed with $4 \%$ PFA and washed, and coverslips were mounted with Fluorosave.

Filter implants. Twenty-four hours after cell plating, cultures were fixed with $4 \%$ PFA, permeabilized with $0.05 \%$ Triton X-100 (in PBS), and blocked with 3\% BSA, 1\% normal goat serum (NGS) (Invitrogen) in PBS. Mouse monoclonal anti- $\beta$ III tubulin (1:400; Sigma-Aldrich) and rabbit polyclonal anti-glial fibrillary acidic protein (GFAP) antibody (1: 400; Sigma-Aldrich) (diluted in block) were incubated overnight at $4^{\circ} \mathrm{C}$. Filters were incubated with goat anti-rabbit biotinylated antibody in PBS followed by an incubation in Cy3-streptavidin in PBS. Filters were mounted with Fluorosave onto slides.

Cells were analyzed with light and fluorescent microscopy and mean neurite length was measured in micrometers using Open Lab software. All neurite outgrowth assays were repeated at least three times. The mean of 50 randomly chosen neurites was plotted in graphs. Statistical analysis was performed using ANOVA followed by post hoc analysis using SigmaStat software.

Western blot analysis of PC12 cells and PC12 conditioned medium Cell lysates of differentiated PC12, $\alpha 4 / \alpha 4, \alpha 5 / \alpha 5, \alpha 9 / \alpha 9, \alpha 9 / \alpha 4, \alpha 9 / \alpha 5$, $\alpha 5 / \alpha 9$, and $\alpha 9$ woCYT cells were prepared in extraction buffer [150 mM $\mathrm{NaCl}, 1 \%$ NP-40, 0.5\% DOC, $0.1 \%$ SDS, 50 mm Tris-HCl, pH 7.5, 20 mm EDTA, complete protease inhibitor (Roche), $10 \mu \mathrm{g} / \mathrm{ml}$ pepstatin A] after $48 \mathrm{~h}$ in culture. Serum-free conditioned media (control and transduced PC12 cells) were prepared with complete protease inhibitor and centrifuged. Supernatants were concentrated for high molecular weight molecules by centrifuging in Millipore columns (Millipore) with a $100 \mathrm{kDa}$ size limit. Protein content was determined with a Protein Assay kit (Bio$\mathrm{Rad}$ ). Samples were prepared with $20 \mu \mathrm{g}$ of protein (cell lysates) or $40 \mu \mathrm{g}$ (conditioned media) mixed with $5 \times$ SDS-sample buffer under reducing conditions. Samples were boiled for $5 \mathrm{~min}$ and run on 5\% SDS-PAGE (or $10 \%$ for osteopontin) and transferred to Hybond-C membranes (GE Healthcare). Membranes were blocked in 5\% milk powder/TBS-T and incubated with mouse monoclonal anti-osteopontin (1:1000; Millipore Bioscience Research Reagents), rabbit polyclonal $\alpha$-TN-C (KAF14; 1:500) (Faissner and Kruse, 1990), and rabbit IgG used at $1 \mu \mathrm{g} / \mathrm{ml}$, and were incubated for $2 \mathrm{~h}$ at room temperature. For $\alpha 9$ integrin Western blot analysis, 10\% SDS-PAGE gels were run and probed with anti-human $\alpha 9$ integrin (1:2000; chicken polyclonal; Abcam) and anti-actin (1:5000; mouse monoclonal; Calbiochem). Protein bands were visualized with peroxidase-conjugated anti-mouse, anti-rabbit, or anti-chicken IgG (100 $\mathrm{ng} / \mathrm{ml}$; Vector Laboratories) and chemiluminescence (ECL; GE Healthcare).

\section{$R N A$ interference of tenascin- $C$}

Suppression of TN-C protein expression was performed by RNA interference using three specific short interfering RNA (siRNA) oligonucleotides purchased from Dharmacon (Thermo Fisher Scientific) targeted to different regions within the rat TN-C mRNA sequence. The TN-C siRNA sequences correspond to 5'-GUGGAGAGUUUCCGGAUUAUU-3', 5' UGGCCAAGUUUGAUCGUUAUU- ${ }^{\prime}$, and $5^{\prime}$-GUGAGGACUUCUAUCGAAAUU- $3^{\prime}$ of the rat mRNA sequence. Differentiated $\alpha 9$ integrin- expressing PC12 cells (previously transduced with lentivirus, LV-a9IRES-fGFP) (see above) grown on laminin $(10 \mu \mathrm{g} / \mathrm{ml})$ were transfected with either scrambled control oligonucleotide (Ambion) or with the tenascin-C oligonucleotides in DMEM (Invitrogen) with Dharmafect transfection reagent (Dharmacon) at $100 \mathrm{~nm}$ concentration and incubated for $4 \mathrm{~h}$ at $37^{\circ} \mathrm{C}$, after which the medium was replaced with fresh PC12 cell differentiation medium. Ninety-six hours after transfection, cells were replated onto coated (laminin or tenascin-C; both at $10 \mu \mathrm{g} / \mathrm{ml}$ ) or uncoated chamber slides. Neurite outgrowth was assessed $48 \mathrm{~h}$ later as described above using immunocytochemistry for green fluorescent protein (GFP). Tenascin-C expression was also examined using rabbit polyclonal $\alpha$-TN-C (KAF14; 1:400) (Faissner and Kruse, 1990). $\alpha 9$ integrinexpressing PC12 cells identified with GFP immunoreactivity were analyzed for the presence or absence of neurites along with the presence or absence/reduction in the level of tenascin-C immunoreactivity. Outgrowth assays were repeated three times, and statistical analysis was performed using a two-way ANOVA test followed by post hoc analysis. Additionally, cell lysates were prepared for Western blotting analysis as described above and assessed for tenascin-C protein levels using $10 \mu \mathrm{g}$ of protein. Densitometry analysis of tenascin-C expression was performed with ImageJ software (National Institutes of Health) with control level values (wild-type PC12 cells) set to 1 and experimental values compared with control levels.

\section{Reverse transcription-PCR}

To generate probes for rat $\alpha 9$ integrin, primer pairs were generated and used in PCRs. The pair of primers used to make the probe was as follows: 5' -CAG ACG GTA TAC TTA CCT GGG C-3' (sense) and 5'-CAG CCG TCA GAT TGT AGT TCA G-3' (antisense) with an expected size of 830 bp. A second pair of primers, 5'-CTG AAC TAC AAT CTG ACG GCT G-3' (sense) and 5'-GCT GAG AAT TTC CTC TTC TCC-3' (antisense), was used and gave a product at the expected size of $683 \mathrm{bp}$. As control, primers against GAPDH were used. PCR products were separated on $1.7 \%$ agarose gels and the expected band at $830 \mathrm{bp}$ was excised and gel purified according to the manufacturer's protocol (QIAGEN). Densitometry analysis of changes in $\alpha 7$ or $\alpha 9$ integrin mRNA expression was performed with ImageJ software as described for Western blot analysis with uninjured/control values set to 1 and experimental values compared with controls.

\section{$\alpha 9$ in situ hybridization}

Probes were generated with PCR using primers for rat $\alpha 9$ integrin $5^{\prime}$ CAGACGGTATACTTACCTGGGC-3' (sense) and 5' -CAGCCGTCAGATTGTAGTTCAG-3' (antisense) or for human $\alpha 9$ integrin 5' -GGAGGGGATGATGTAGCAGAA-3' (sense) and 5' -AGCCGGACGCCAGAGTCCCCT-3' (antisense). Additionally, GFP probes were generated using the primers $5^{\prime}$-TGTTCAGGTAGTGGTTGTCGG-3' (sense) and 5' CCTGAAGTTCATCTGCACCAC-3' (antisense). Procedure for in situ hybridization was performed as previously described (Carulli et al., 2006). Postnatal day 0 (P0) and adult male Sprague Dawley rats were killed, and cervical DRGs were removed and embedded in OCT and frozen on dry ice. DRGs were sectioned at $16 \mu \mathrm{m}$ thick on a cryostat and air-dried for $30 \mathrm{~min}$. To immunolabel neurons, sections were labeled overnight at $4^{\circ} \mathrm{C}$ with rabbit anti-neurofilament (3A10) antibody and washed three times with PBS. Subsequently, slides were incubated with secondary biotin-conjugated goat anti-rabbit IgG (GE Healthcare), rinsed with PBS, and incubated with Cy3-linked streptavidin (GE Healthcare) and Hoechst (Sigma-Aldrich). Slides were rinsed in PBS and coverslips were mounted with Fluorosave. DRGs were analyzed with light and fluorescence microscopy.

\section{Surgeries}

Experiments were conducted in accordance with the United Kingdom Animals (Scientific Procedure) Act of 1986. Adult male (250-350 g) Lister-Hooded rats (Charles River Laboratories) were used for in vivo experiments. Food and water were provided ad libitum, and there was $12 \mathrm{~h}$ light/dark exposure. During surgery, rats were anesthetized in 1-2\% isoflurane, in a mixture of $50 \%$ nitrous oxide and $50 \%$ oxygen.

Dorsal root injury groups ( $n=3$ for each $\alpha 9$ plus fGFP or fGFP) sustained a dorsal root injury concurrent with the DRG injections. Under 
anesthesia, a left-side hemilaminectomy was performed at cervical levels C5-C8 and thoracic level T1, to unilaterally expose C5-C8 DRGs and dorsal roots. Injections were performed using a $10 \mu \mathrm{m}$ pulled glass capillary attached to a 26-gauge $10 \mu \mathrm{l}$ Hamilton syringe (Hamilton Company) driven by an infusion syringe pump (Harvard Apparatus) at 0.2 $\mu \mathrm{l} / \mathrm{min}$. One microliter of AAV-fGFP plus sterile PBS or AAV-fGFP plus AAV-a9 integrin $\left(1.2 \times 10^{12}\right.$ viral particles/ml total for each $)$ was injected into the DRGs (C6 and C7) over a $5 \mathrm{~min}$ period, followed by a 3 min period before capillary removal. A quadruple dorsal root crush $(3 \times$ $10 \mathrm{~s} /$ root) was performed concurrent to the DRG injections, unilaterally at C5-C8. Additional animals underwent DRG injection as described but without dorsal rhizotomy and were used for Western blot analysis, for DRG cultures, or for in situ hybridization studies. In these cases, DRGs were harvested 3 weeks after injection. For Western blot analysis, a saline extraction was performed initially to remove blood vessels and debris, followed by sample preparation as described previously. For explant cultures, DRGs were prepared as described previously and plated immediately onto uncoated chamber slides (plastic) or chamber slides coated with tenascin-C $(10 \mu \mathrm{g} / \mathrm{ml})$ or laminin $(10 \mu \mathrm{g} / \mathrm{ml})$. Ninety-six hours after plating, neurite outgrowth was assessed using phase microscopy. Imaging was performed using a Leica inverted microscope (Leica). For in situ hybridization analysis, animals were administered an overdose of sodium pentobarbitol and transcardially perfused with saline and $4 \%$ PFA. Sections were processed as described above for in situ hybridization.

Dorsal column injury groups ( $n=4$ for each $\alpha 9$ plus fGFP or fGFP) sustained a dorsal column injury concurrent with an injection of AAV into the DRGs. Under anesthesia, a laminectomy was performed at cervical levels C4 and C5 to expose the dorsal surface of the spinal cord. The dura was retracted and the dorsal columns, identified within the immediate extents of the dorsal root entry zones on either side, were crushed bilaterally for $10 \mathrm{~s}$ using finely milled forceps at a depth of $2 \mathrm{~mm}$. During the same surgery, a hemilaminectomy was performed on the left side at cervical levels C5-C7 to fully expose the C6 and C7 DRGs. DRG injections were performed as described above.

\section{Sensory behavioral testing and analysis}

Rats were tested 1 week before surgery and 5 weeks after surgery. For testing, rats were placed in Plexiglas containers with a wire mesh floor (pressure test) or a Plexiglas floor (hot-plate test), and acclimatized to the testing chamber for $10 \mathrm{~min}$.

Pressure test/mechanical hyperalgesia. A testing probe used to assess fine touch and mechanical hyperalgesia was measured with an electronic anesthesiometer (model 1601C; Life Science Instruments). The probe was applied to the glaborous foot pad of the left forepaw and pressure was increased until the rat withdrew its paw. If the rat did not withdraw its paw with $100 \mathrm{~g}$ of force, the test was terminated. Pressure (maximum force) at paw withdrawal was recorded with a force transducer measured in grams. Five trials were performed on the same paw during the testing period with the lowest and highest recordings discarded.

Hot-plate test/thermal hyperalgesia. A movable infrared light source (Ugo Basile) was placed under the center of the foot pad of the left forepaw. The time (in seconds) at which the animal withdrew its paw after the stimulus began was recorded. If the rat did not withdraw its paw with $20 \mathrm{~s}$ of heat stimulus, the test was terminated. Three trials were performed during testing session. For both tests, preoperative withdrawal force or latencies were compared with postoperative levels using a one-way ANOVA.

\section{Immunohistochemistry}

Six weeks after surgery, animals were administered an overdose of sodium pentobarbital and transcardially perfused with $500 \mathrm{ml}$ of saline in $\mathrm{PB}, \mathrm{pH} 7.4$, followed by $500 \mathrm{ml}$ of $4 \%$ PFA, pH 7.4. A $2 \mathrm{~cm}$ section of spinal cord with the lesion site at the epicenter (dorsal column-injured group) or a $1 \mathrm{~cm}$ section of spinal cord with attached injured roots with injected DRGs (dorsal rhizotomy group) was removed and postfixed in $4 \%$ PFA before cryoprotection overnight in $30 \%$ sucrose in $0.1 \mathrm{M} \mathrm{PB}, \mathrm{pH}$ 7.4. Tissue was embedded in OCT (RALamb UK) and sectioned transversely (dorsal rhizotomy group) at $20 \mu \mathrm{m}$ thickness or longitudinally (dorsal column injured group) on a cryostat at $14 \mu \mathrm{m}$ thickness and mounted on slides (Superfrost Plus; VWR International).
Sections were washed with PBS and blocked in 10\% NGS, 0.4\% Triton X-100 in PBS. Primary antibodies, anti- $\beta$ III tubulin (1:400; mouse; Sigma-Aldrich), anti-GFP (1:500; rabbit; Invitrogen), anti-GFAP (1:400; mouse; Sigma-Aldrich), or anti-TN-C (Kaf14; 1:200; rabbit), were incubated overnight at $4^{\circ} \mathrm{C}$. Sections were rinsed in triplicate in $0.1 \mathrm{M}$ PBS and incubated with secondary antibodies (1:200; goat anti-mouse or rabbit Alexa Fluor 568 or 488; Invitrogen). Slides were rinsed and coverslipped with Fluorosave.

\section{Microscopy and analysis}

Imaging was performed using a Leica DM6000 microscope or a Leica TCS SP2 confocal microscope (Leica). In the dorsal rhizotomy group, axons were quantitated as the number of axons crossing a line drawn in the dorsal root proximal to the crush site, axons from the DREZ were quantitated within the entry zone demarcated by GFAP immunohistochemistry, and axons within the spinal cord were quantitated if they were in the spinal cord beyond the DREZ. In the dorsal column-injured group, axons were quantitated within the lesion site, demarcated by GFAPimmunoreactive boundaries. Numbers of axons in both groups were quantitated from six sections throughout injured dorsal root and expressed as numbers of axons per animal. Comparisons were made between the AAV- $\alpha 9$ group and the AAV-fGFP group in the specified regions using one-way ANOVA and post hoc analysis.

\section{Results}

\section{Expression of $\alpha 9$ integrin in PC12 cells overcomes inhibition of neurite outgrowth by tenascin-C}

To promote neurite growth on TN-C, we first determined which integrins increase neurite outgrowth from PC12 cells plated on TN-C. Human $\alpha 9$ integrin, $\alpha 4$ integrin, and $\alpha 5$ integrin were overexpressed in differentiated PC12 cells. Untransfected PC12 cells (Fig. 1A) or PC12 cells transduced with fGFP (Fig. 1B) extended long neurites on laminin (average length $50.4375 \mu \mathrm{m}$ ), but PC12 cells did not extend neurites on TN-C or on uncoated tissue culture plastic (average length, $0 \mu \mathrm{m}$ on TN-C or plastic) (Fig. $1 A, C, D$ ). Tenascin-C is a ligand for the $\alpha 9 \beta 1$ integrin heterodimer, binding to the nonalternatively spliced fn 3 domain of TN-C (Yokosaki et al., 1994, 1998). To determine whether expression of the $\alpha 9$ integrin subunit in PC12 cells was capable of stimulating neurite outgrowth specifically on TN-C, PC12 cells were transduced with the human integrin subunits $\alpha 9$, and as controls $\alpha 4$ [a receptor for vascular cell adhesion molecule-1 (VCAM-1) and thrombospondin], and $\alpha 5$ (a receptor for fibronectin). Neurite outgrowth on laminin was not affected by transfection with any of the $\alpha$ subunits, with similar lengths to untransfected PC12 cells. Only $\alpha 9$ integrin-expressing PC12 cells showed significant neurite outgrowth on TN-C and on plastic (Fig. 1A,F,G).

Previous studies by Vogelezang et al. $(2001,2007)$ determined the $\alpha 4$ integrin cytoplasmic domain to be necessary for neurite outgrowth from PC12 cells on fibronectin. To determine the contribution of extracellular and cytoplasmic domains of $\alpha 9$ integrin to neurite outgrowth on TN-C, chimeric constructs of different integrin domains were tested. Four different constructs were used to transfect PC12 cells including $\alpha 5 / \alpha 9$ (extracellular domain $\alpha 5 /$ cytoplasmic domain $\alpha 9$ ), $\alpha 9 / \alpha 4$ (extracellular domain $\alpha 9 /$ cytoplasmic domain $\alpha 4$ ), $\alpha 9 / \alpha 5$ (extracellular domain $\alpha 9 /$ cytoplasmic domain $\alpha 5$ ), and $\alpha 9$ with a deletion of the cytoplasmic domain. The cells were grown on laminin, TN-C, and plastic. All of the PC12 cells grew long neurites on laminin similarly to untransfected cells (Fig. $1 B$ ). However, on TN-C or plastic, PC12 cells transfected with $\alpha 9 / \alpha 4, \alpha 9 / \alpha 5$, and $\alpha 9$ without the cytoplasmic domain all extended neurites similar to the outgrowth on laminin, whereas the $\alpha 5 / \alpha 9$-transfected PC1 2 cells (the only construct lacking the $\alpha 9$ integrin extracellular domain) did not extend neurites (Fig. $1 B$ ). 

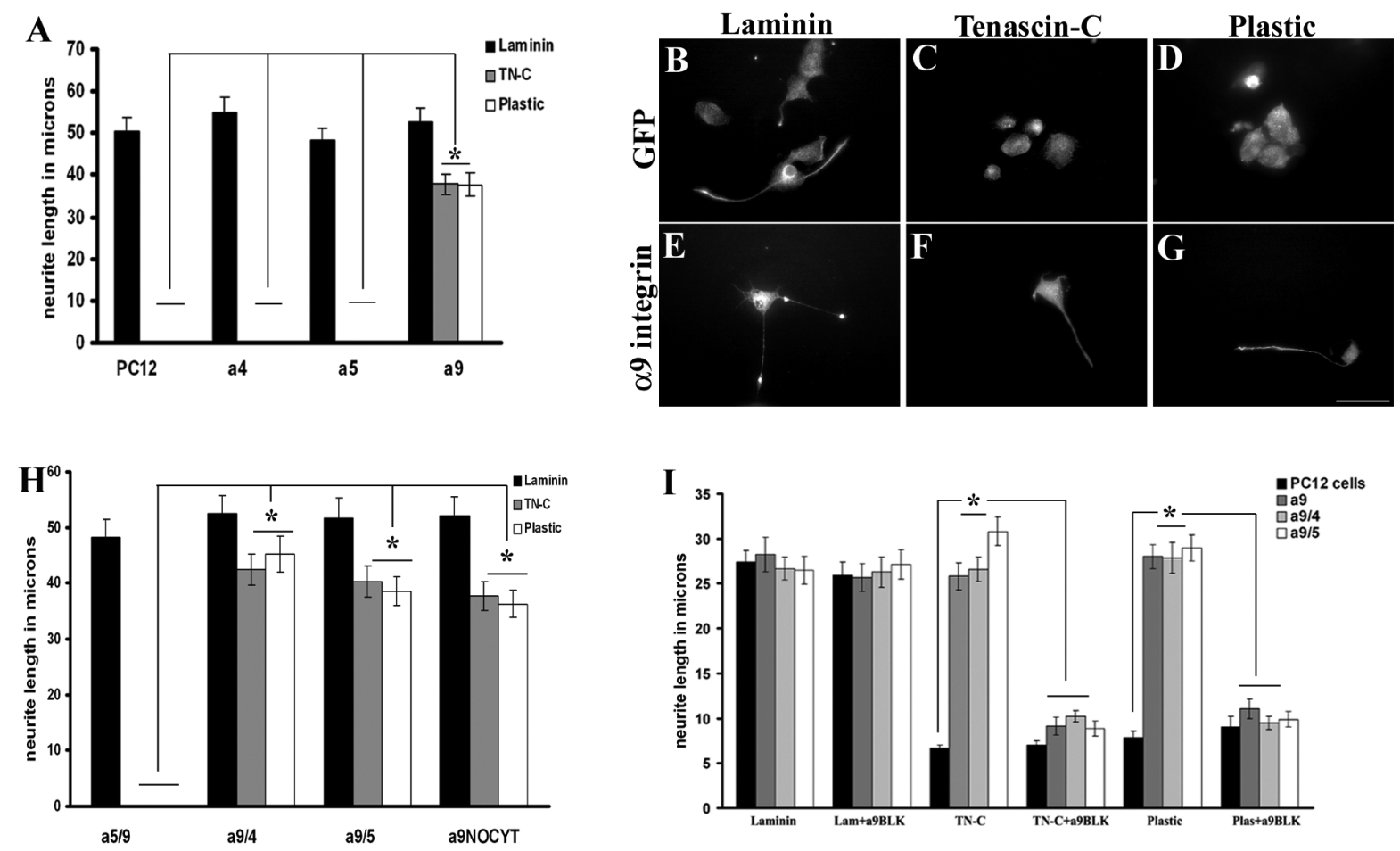

Figure 1. PC12 cells overexpressing $\alpha 9$ integrin extend neurites on TN-C, independent of the cytoplasmic domain. $\boldsymbol{A}$, Quantification of neurite length from differentiated PC12 cells at $48 \mathrm{~h}$, mock transfected or transfected with $\alpha 4, \alpha 5$, or $\alpha 9$ integrin. The asterisk $\left(^{*}\right)$ indicates significantly ( $\left.p<0.05\right)$ greater neurite outgrowth in $\alpha 9$-expressing PC12 cells on TN-C and plastic compared with mock transfected, $\alpha 4$, and $\alpha$ 5-expressing PC12 cells. $\boldsymbol{B}-\mathbf{G}$, Immunofluorescent labeling of neurofilament in PC12 cells transduced with a lentivirus expressing fGFP ( $\boldsymbol{B}$ - $\boldsymbol{D}$ ) or $\alpha 9$ integrin-IRES-fGFP $(\boldsymbol{E}-\mathbf{G})$ grown on laminin $(\boldsymbol{B}, \boldsymbol{E})$, TN-C $(\boldsymbol{C}, \boldsymbol{F})$, or plastic $(\boldsymbol{D}, \boldsymbol{G})$. $\boldsymbol{H}$, Quantification of neurite length from differentiated PC12 cells at $48 \mathrm{~h}$, mock transfected or transfected with $\alpha 9$ integrin constructs $\left(\alpha 5 / \alpha 9, \alpha 9 / \alpha 4, \alpha 9 / \alpha 5, \alpha 9\right.$ NOCYT). The asterisk ( $\left.{ }^{*}\right)$ indicates significantly $(p<0.05)$ greater neurite outgrowth on TN-C or plastic in the presence of the $\alpha 9$ extracellular domain. I, Quantification of neurite length from differentiated PC12 cells at 24 h, mock transfected or transfected with $\alpha 9 / \alpha 9, \alpha 9 / \alpha 4$, or $\alpha 9 / \alpha 5$ incubated in the presence or absence of anti-human $\alpha 9 \beta 1$ blocking antibody ("a9BLK"). All neurite outgrowth assays were repeated three times. The length of at least 50 randomly selected neurons was analyzed. The asterisk $\left(^{*}\right)$ indicates significantly $(p<0.05)$ less neurite outgrowth with $\alpha 9 \beta 1$ blocking antibody treatment of $\alpha 9$ integrin-expressing PC12 cells on TN-C or plastic. Error bars indicate SEM. Scale bar, $50 \mu \mathrm{m}$.

To verify the specificity of the effect of $\alpha 9$ integrin on neurite outgrowth, an $\alpha 9 \beta 1$ integrin blocking antibody was used. Previous studies using the $\alpha 9 \beta 1$ integrin blocking antibody, Y9A2, have successfully abolished $\alpha 9 \beta 1$ substrate binding (Vlahakis et al., 2005, 2007). PC12 cells, either untransfected or transfected with $\alpha 9$ constructs (extracellular domain) and grown on laminin, extended long neurites unaffected by the presence of the $\alpha 9 \beta 1$ integrin blocking antibody (Fig. 1C). In contrast, transfected cells grown on TN-C or on plastic in the presence of the $\alpha 9 \beta 1$ integrin blocking antibody extended significantly shorter neurites than without the blocking antibody, reversing the effect of the $\alpha 9$ integrin (Fig. 1C).

$\alpha 9$ integrin induces neurite outgrowth from PC12 cells on injured and uninjured cortical tissue

Next, we determined whether $\alpha 9$ integrin was capable of inducing neurite outgrowth on two physiological substrates, cortical cryosections and nitrocellulose filters that had been previously embedded into cortical injuries. PC12 cells, untransfected or transfected with $\alpha 9$ integrin constructs $(\alpha 9 / \alpha 9, \alpha 9 / \alpha 4$, and $\alpha 9 /$ $\alpha 5)$, were grown for $24 \mathrm{~h}$ on uninjured cortical cryosections. PC1 2 cells transfected with the $\alpha 9$ integrin subunits were able to extend significantly longer neurites on cortical cryosections than untransfected PC12 cells (Fig. 2A,B,E). To determine whether the neurite outgrowth was dependent on $\alpha 9$ integrin, an $\alpha 9 \beta 1$ integrin blocking antibody was added to the cultures. This resulted in a significant reduction in neurite length compared with the untreated groups (Fig. 2C-E).

Nitrocellulose filters that had been implanted into cortical stab lesions for $14 \mathrm{~d}$ after lesion were used as growth substrates for the PC12 cells. These filters become enriched with glial scar components such as TN-C and reactive astrocytes, including increased levels of GFAP (McKeon et al., 1995). PC12 cells, untransfected or transfected with the $\alpha 9$ integrin chimeras, were grown on nitrocellulose filters for $24 \mathrm{~h}$. Untransfected PC12 cells grew very short neurites compared with $\alpha 9$ integrintransfected PC12 cells, which grew significantly longer neurites (Fig. $2 F$ ). The inclusion of the $\alpha 9$ integrin blocking antibody abrogated this effect, decreasing neurite outgrowth (Fig. $2 F)$. In conclusion, the results from Figures 1 and 2 demonstrate that the expression of $\alpha 9$ integrin enables PC12 cells to grow long neurites on tenascin-rich surfaces, the effect being dependent on the $\alpha 9$ extracellular domain.

PC1 2 cells express the $\alpha 9$ integrin ligand, tenascin-C $\alpha 9$ integrin-expressing PC12 cells but not control cells or cells expressing other integrins extend long neurites on tissue culture plastic, suggesting that PC12 cells may express and/or secrete their own ligands for $\alpha 9$ integrin. Two ligands for $\alpha 9$ integrin are the extracellular matrix molecules TN-C (Smith et al., 1996; Yokosaki et al., 1998) and osteopontin (Yokosaki et al., 1999). Cell extracts and conditioned media from PC12 cells (untransfected and transfected subtypes) were analyzed by Western blot to determine levels of TN-C and osteopontin. Using antibodies against full-length TN-C, we detected TN-C in both the cell extracts and in the conditioned media (Fig. $3 A$ ). To further confirm expression in cultured PC12 cells, untransfected cells were immunolabeled for TN-C, in which case full-length TN-C was de- 

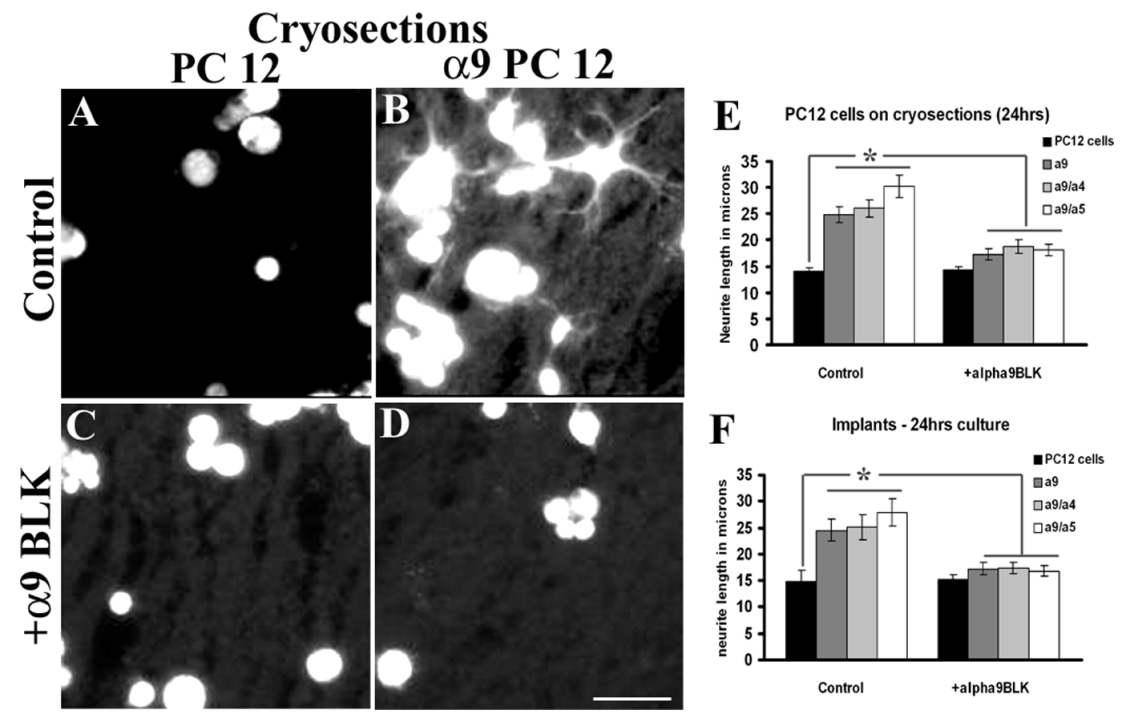

Figure 2. $\alpha 9$ integrin induces neurite outgrowth on adult rat cortical cryosections or on nitrocellulose filter implants from cortical lesions. Differentiated control $(\boldsymbol{A}, \boldsymbol{C})$ or $\alpha 9 / \alpha 9(\boldsymbol{B}, \boldsymbol{D})$ integrin-expressing PC12 cells (labeled with Cell Tracker Green) grown on cortical cryosections for $24 \mathrm{~h}$, in the presence of anti-human $\alpha 9 \beta 1$ antibody, a9BLK (C, D). Quantification of neurite outgrowth of PC12 cells expressing human $\alpha 9 / \alpha 9, \alpha 9 / \alpha 4$, or $\alpha 9 / \alpha 5$ grown on cortical cryosections for $24 \mathrm{~h}$ ( $\boldsymbol{E}$ ) or grown on filter implants $(24 \mathrm{~h}$ ) from 14-d-old cortical lesions $(\boldsymbol{F})$ incubated in the presence or absence of anti-human $\alpha 9 \beta 1$ blocking antibody. Neurite outgrowth assays were repeated three times. The length of at least 50 randomly selected neurons was analyzed. The asterisk ( ${ }^{*}$ ) indicates significantly $(p<0.05)$ greater neurite outgrowth of $\alpha 9$ chimeras on TN-C and plastic. Error bars indicate SEM. Scale bar, $100 \mu \mathrm{m}$.

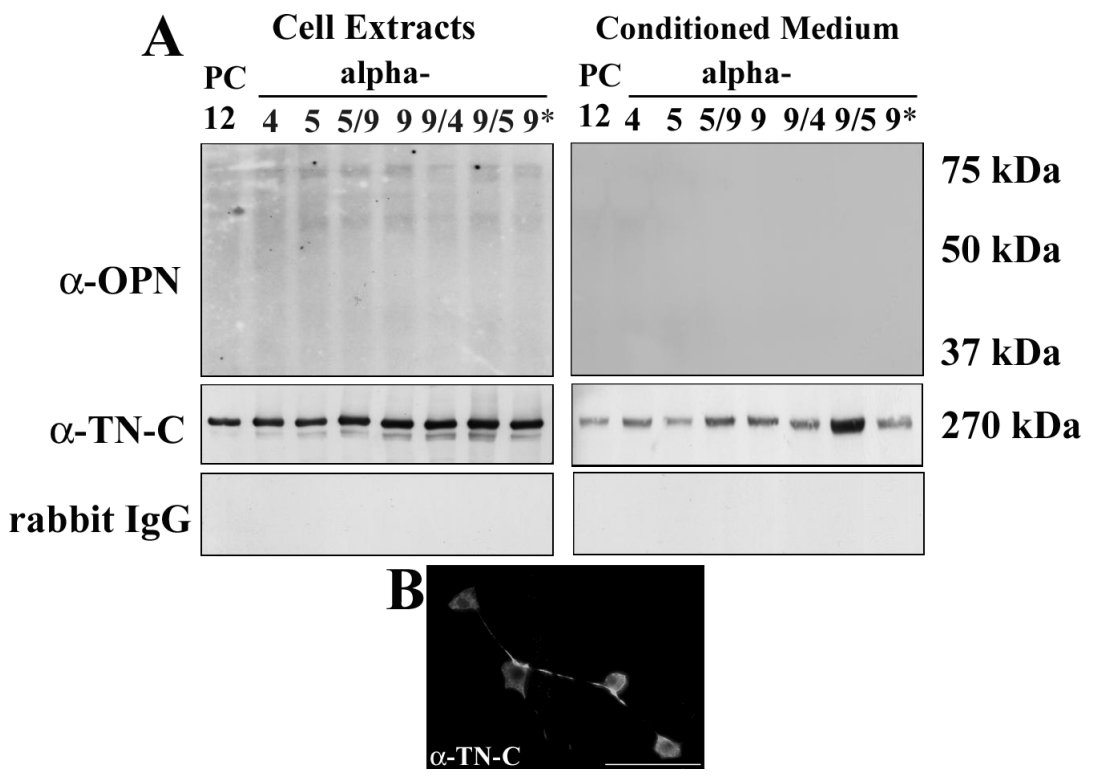

Figure 3. $\mathrm{PC} 12$ cells express TN-C. $A$, Western blot analysis of cell extracts (left panels) and conditioned media (right panels) from differentiated PC12 cells transfected with the human integrins $\alpha 4, \alpha 5, \alpha 5 / \alpha 9, \alpha 9 / \alpha 9, \alpha 9 / \alpha 4, \alpha 9 / \alpha 5$, or $\alpha 9$ lacking the entire cytoplasmic domain $\left(\alpha 9^{*}\right)$ cultured for $48 \mathrm{~h}$ on PDL and examined for expression of osteopontin and full-length TN-C. Western blots were probed with rabbit lgG as a control. B, Full-length TN-Cimmunostaining in differentiated PC12 cells. Scale bar, $50 \mu \mathrm{m}$.

tected in the cell bodies and processes of PC12 cells (Fig. 3B). Osteopontin was not detected in either the PC12 cell extracts or the PC12 cell conditioned media (Fig. 3A). Rabbit IgG was used as a control to show the specificity of the TN-C antibody and was also not detected (Fig. 3A). The other two $\alpha 9$ integrin ligands are fibronectin and VCAM-1. These cannot have been secreted in sufficient amounts to promote autocrine neurite growth, because neither transfection with $\alpha 4$ (a VCAM ligand) or $\alpha 5$ (a fibronectin ligand) promoted neurite growth on plastic.
Adult dorsal root ganglia neurons expressing $\alpha 9$ integrin extend neurites on TN-C

The ability of primary neurons to extend neurites on TN-C and plastic compared with laminin was examined to further determine the ability of $\alpha 9$ integrin to enhance neurite outgrowth in vitro. DRG explants plated on TN-C or plastic did not extend neurites (Fig. 4B,C); however, many long neurites extended from explants plated on laminin (Fig. $4 A$ ). In dissociated DRG cultures, neurons were transduced with adenovirus expressing either $\alpha 9$ integrin or LacZ as a control (Fig. $4 P$ ), or using lentivirus to express $\alpha 9$ integrin with fGFP under an IRES promoter or fGFP alone as a control (Fig. 4D-O). Dissociated DRGs expressing fGFP grown on TN-C or plastic did not extend neurites (Fig. $4 E, F, H, I) . \alpha 9$ integrin-expressing DRGs grown on TN-C or plastic extended long neurites (Fig. $4 K, L, N-P$ ), similar to the outgrowth observed on laminin (Fig. $4 D, G, J, M, P)$.

Consistent with the PC12 cell experiments, neurite outgrowth was observed on tissue culture plastic after expression of $\alpha 9$ integrin. Immunostaining of dissociated DRGs for full-length TN-C revealed its presence throughout the cell body and processes. In addition, TN-C labeling was detected on the surrounding substrate showing that some of the secreted TN-C adhered to the culture surface (Fig. 4Q,R).

We confirmed that $\alpha 9$-transfected PC12 cells can grow neurites on uncoated plastic because they lay down their own matrix of tenascin-C. We used RNA interference (siRNA) to reduce the levels of tenascin- $\mathrm{C}$ protein in $\alpha 9$ cells, and then tested whether they could still grow neurites on plastic. Western blot analysis confirmed that levels of tenascin- $\mathrm{C}$ were greatly decreased after incubation with tenascin-C siRNA compared with wild-type PC12 cells (supplemental Fig. 1I, available at www. jneurosci.org as supplemental material). Tenascin-C siRNA treated $\alpha 9$-expressing cells showed a marked reduction in the number of cells extending neurites on plastic. However, they retained their ability to grow neurites on tenascin-C or laminin (supplemental Fig. S1 $A-H$,J, available at www.jneurosci.org as supplemental material). Neurite outgrowth was not affected in $\alpha 9$ integrin-expressing cells grown on plastic transfected with control siRNA (supplemental Fig. $S 1 C, D$, available at www.jneurosci.org as supplemental material).

$\alpha 9$ integrin is not expressed by adult rat DRGs nor is it upregulated after injury

To determine whether adult DRGs express $\alpha 9$ integrin, we performed in situ hybridization for $\alpha 9$ integrin. Sections of adult rat 
DRGs were labeled with $\alpha 9$ antisense and sense probes and costained with an antibody against neurofilament, 3A10 (Fig. 5A-H). We did not detect any labeling with either the $\alpha 9$ integrin sense or antisense probe (Fig. $5 E, H)$. In previous studies by our laboratory, we observed P0 rodent DRG explants successfully elongating neurites on TN-C (our unpublished observations) in contrast to adult DRG explants. In P0 DRG sections, the antisense probe detected $\alpha 9$ integrin mRNA (Fig. $5 A$ ), with minor unspecific labeling with the sense probe (Fig. 5D). Counterstaining with 3A10 indicated that the $\alpha 9$ mRNA in the P0 DRG was being produced by neurons (Fig. $5 B$ ). These results suggest that $\alpha 9$ integrin is synthesized in $\mathrm{P} 0$ rat DRG sensory neurons but is developmentally downregulated and absent in adult ganglia.

After injury to the CNS or PNS, many changes in gene expression occur, including the modification of integrin expression, such as an increase in $\alpha 7 \beta 1$ after PNS injury (Werner et al., 2000; Gardiner et al., 2005) or an increase in $\alpha 1 \beta 1$ and $\alpha 6 \beta 1$ in the macrophages/microglia and blood vessels surrounding a spinal cord contusion injury (Baker and Hagg, 2007). To determine whether levels of $\alpha 9 \beta 1$ integrin were also modified in the adult after injury, the sciatic nerve was crushed and levels of $\alpha 9 \beta 1$ were determined by reverse transcription (RT)-PCR. Levels of $\alpha 7$ were examined as a control since it is known to be upregulated after peripheral nerve injury. Comparing the DRGs from the injured side to DRGs on the control/uninjured side, $\alpha 7$ was increased over control levels by $4 \mathrm{~d}$ after injury (Fig. 5I ). Levels of $\alpha 9$ in the DRGs of injured and uninjured sides were at the limits of detection, and at 1, 4, and $7 \mathrm{~d}$ after injury, levels of $\alpha 9$ on the injured side did not reach or exceed the levels observed on the control side (Fig. $5 J, K$ ). In the absence of a reliable anti-rodent $\alpha 9$ antibody, these results could not be confirmed with immunohistochemistry.

\section{In vivo $\alpha 9$ integrin expression by adeno-associated virus}

In the above in vitro experiments, retrovirus, adenovirus, and lentivirus were used to transfect or transduct PC12 cells and DRGs in culture. For in vivo experiments, satisfactory transduction of DRG neurons was not achieved with lentivirus as found in other laboratories (M. Mason and J. Verhaagen, personal communication). Additionally, expression induced by adenovirus is transient and inflammation-inducing and therefore not suitable for long-term in vivo studies. We therefore used AAVs because they can transduce a high proportion of neurons in adult DRGs. The disadvantage of this approach is that the coding sequence for GFP-tagged integrins is too large to package into AAVs. To confirm the expression of $\alpha 9$ integrin from our viral vector after AAV
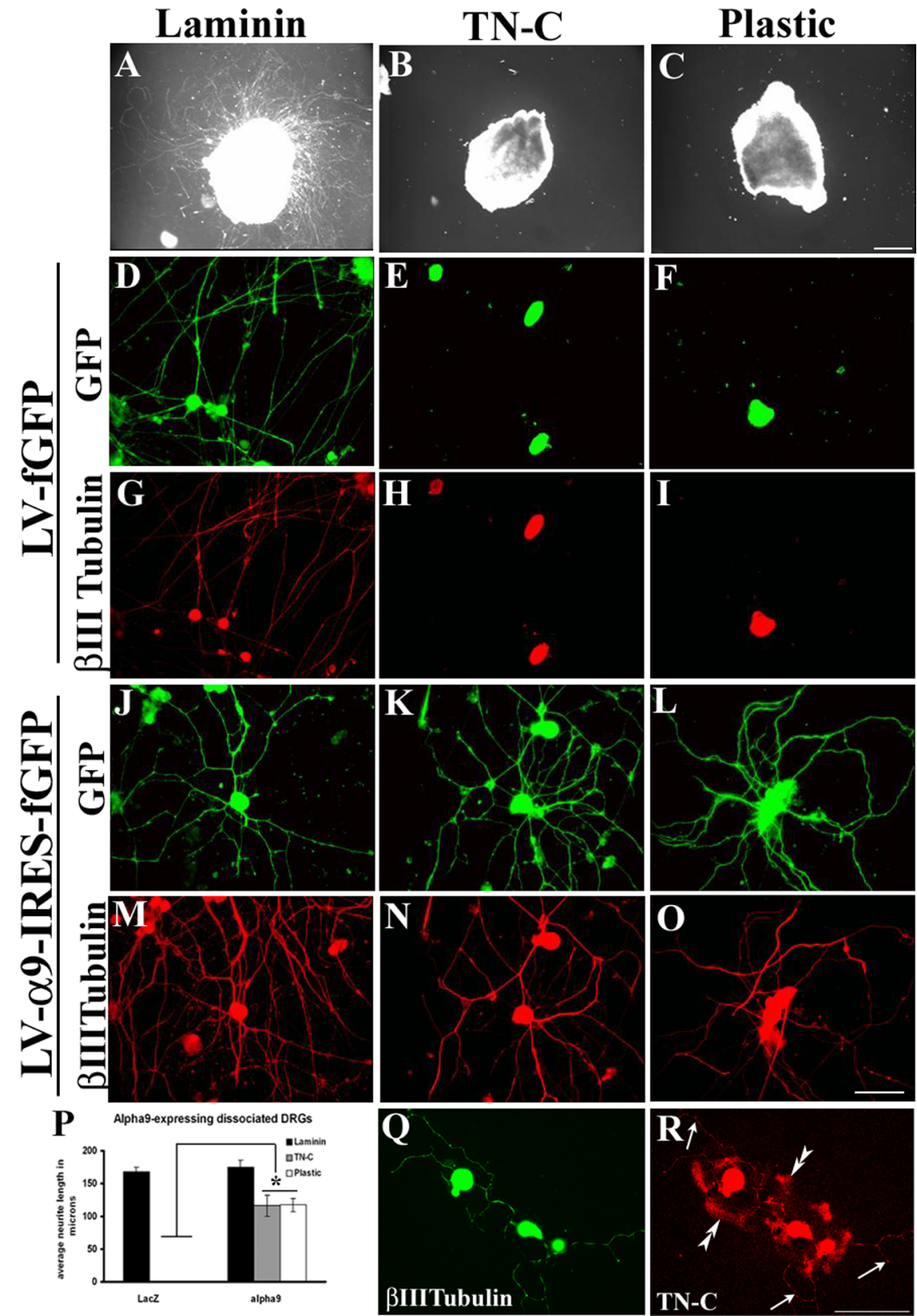

Figure 4. $\alpha 9$ integrin promotes adult sensory neurite outgrowth on TN-C. Adult DRG explants ( $A-C)$ or dissociated DRG neurons transduced with a lentivirus expressing fGFP $(\boldsymbol{D}-\boldsymbol{I})$ or a lentivirus expressing $\alpha$-IRES-fGFP $(\boldsymbol{J}-\mathbf{0})$ were cultured for $72 \mathrm{~h}$ on $10 \mu \mathrm{g} / \mathrm{ml}$ laminin $(\boldsymbol{A}, \boldsymbol{D}, \boldsymbol{G}, \boldsymbol{J}, \boldsymbol{M})$, TN-C $(\boldsymbol{B}, \boldsymbol{E}, \boldsymbol{H}, \boldsymbol{K}, \boldsymbol{N})$, or plastic $(\boldsymbol{C}, \boldsymbol{F}, \boldsymbol{I}, \boldsymbol{L}, \mathbf{O})$. P, Quantification of dissociated DRG neurons transduced with an adenovirus expressing $\alpha 9$ integrin or LacZ plated on laminin, TN-C, or plastic. All neurite outgrowth assays were repeated three times. The length of at least 50 randomly selected neurons was analyzed. The asterisk $\left(^{*}\right)$ indicates significantly $(p<0.05)$ greater neurite outgrowth of dissociated DRGs expressing $\alpha 9$ integrin on TN-C and plastic. Dissociated DRG neurons were immunostained for $\beta$ III tubulin (Q) or TN-C (R). Error bars indicate SEM. Scale bars, $100 \mu \mathrm{m}$.

infection, HEK cells were transduced with the AAVs in vitro, and expression was analyzed by Western blot. Comparing the expression to HEK cells transduced by the lentivirus expressing $\alpha 9$ integrin or transduced by an AAV expressing fGFP, we found that $\alpha 9$ integrin was present in HEKs transduced with both the $\alpha 9$ integrin AAV and lentivirus but not in fGFP-transduced cells (Fig. 6A). Next, we confirmed $\alpha 9$ integrin expression in vivo, 3 weeks after injection of AAV- $\alpha 9$ into cervical DRGs in the adult rat. We analyzed the DRGs by Western blot using anti-human $\alpha 9$ and used the lentiviral $\alpha 9$-transduced HEK cells as a positive 


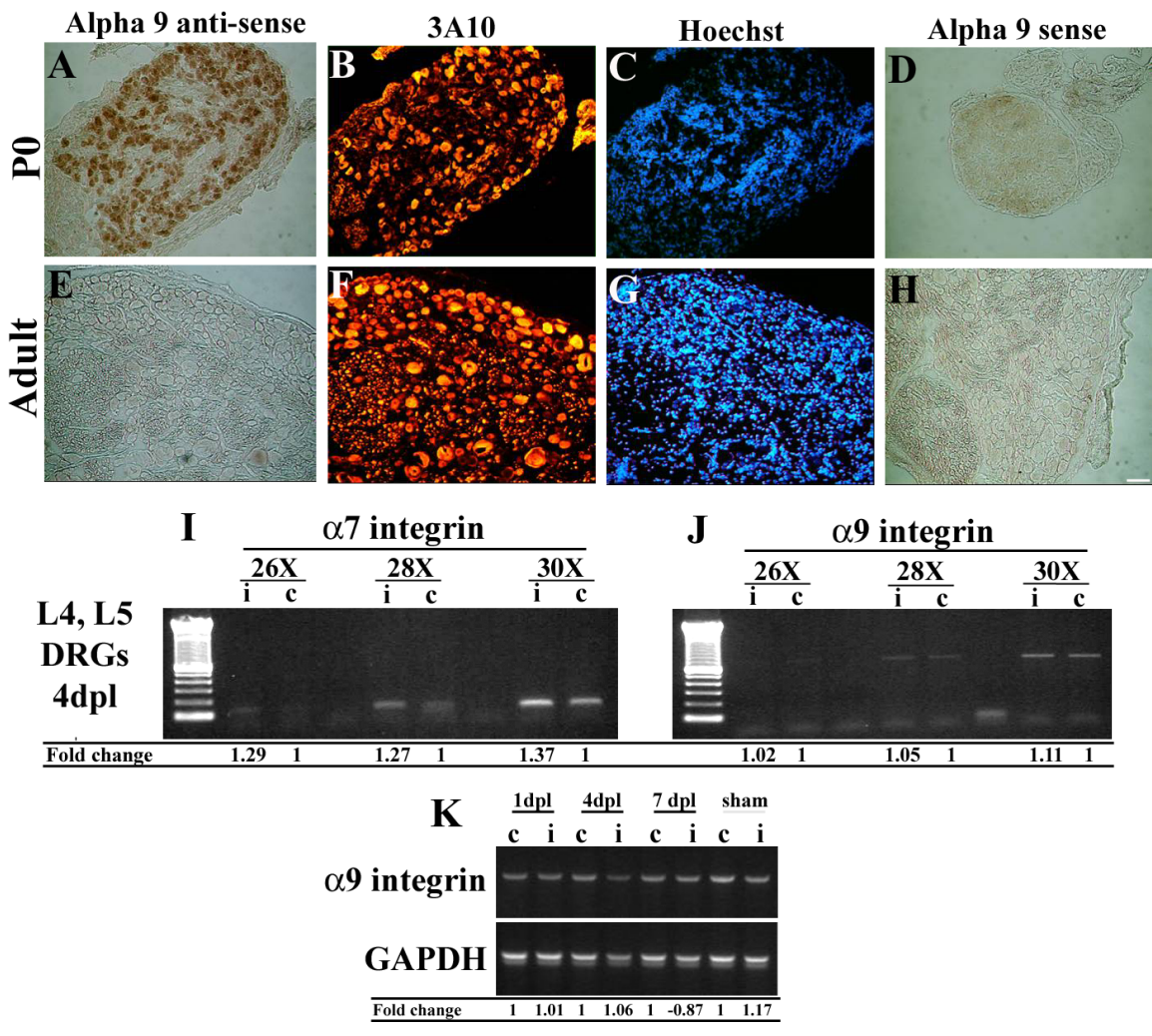

Figure 5. $\alpha 9$ integrin $m R N A$ is expressed in neonate PO DRG neurons, but not in adult sensory neurons, and is not upregulated after nerve injury. Postnatal day $0(\boldsymbol{A}-\boldsymbol{D})$ and adult dorsal root ganglia $(\boldsymbol{E}-\boldsymbol{H})$ were hybridized with antisense $(\boldsymbol{A}, \boldsymbol{E})$ and sense $(\boldsymbol{D}$, $\boldsymbol{H})$ probes against rat $\alpha 9$ integrin. Samples were immunolabeled with anti-neurofilament antibodies $(3 A 10)(\boldsymbol{B}, \boldsymbol{F})$ and Hoechst $(C, G)$. $\alpha 7$ integrin $(I)$ or $\alpha 9$ integrin $(J)$ mRNA expression evaluated by RT-PCR from adult rat lumbar DRGs $(L 4, L 5) 4$ d after sciatic nerve crush from injured (i) and control (c) DRGS. $\boldsymbol{K}, \alpha$ integrin mRNA expression evaluated by RT-PCR from adult rat lumbar DRGs $(L 4, L 5)$ assessed after sciatic nerve crush in both injured (i) and control (c) DRGs over time $(1,4,7 \mathrm{~d}$ after injury). Densitometry of integrin mRNA was performed and the relative changes in $\alpha 7$ integrin $(\boldsymbol{I})$ or $\alpha 9$ integrin $(\boldsymbol{J}, \boldsymbol{K})$ expression after injury compared with control/uninjured levels is shown. Scale bar, $100 \mu \mathrm{m}$.

control and untransduced DRGs as a negative control. Despite low levels of protein overall from the DRGs, we were able to detect a band at the same molecular weight as the $\alpha 9$ integrin from the lentiviral-transduced HEK cells that was of a higher intensity than the control DRGs (Fig. 6B).

We needed to confirm that $\alpha 9$ integrin transduced in vivo into DRG neurons can increase their ability to grow axons on tenascin-C. We made injections of AAV- $\alpha 9$ integrin into DRGs in adult rats, and 3 weeks later these DRGs were removed for in vitro outgrowth assays. DRG explants injected with AAV- $\alpha 9$ integrin or AAV-fGFP were grown on laminin, tenascin-C, or plastic, and analyzed for neurite outgrowth. Similar to our results with lentivirus, adenovirus, and plasmid transfection, we observed a significant increase in neurite outgrowth of AAV- $\alpha 9$ integrinexpressing explants on tenascin-C and plastic compared with AAVfGFP-expressing explants on tenascin-C and plastic (supplemental Fig. S2, available at www.jneurosci.org as supplemental material).

\section{$\alpha 9$ integrin increases dorsal root axon regeneration through TN-C-rich areas}

Encouraged by the extensive neurite outgrowth observed on TN-C in vitro after $\alpha 9$ expression, we examined the ability of sensory axons to regenerate in the dorsal root after AAVmediated transduction of $\alpha 9$ integrin in DRG neurons. For these experiments, the dorsal roots were crushed unilaterally at cervical level 5-8 and two DRGs (C6, C7) and were injected with equal titers of either AAV- $\alpha 9$ integrin plus AAV-fGFP (referred to as
AAV- $\alpha 9)$ or AAV-fGFP plus $1 / 2$ volume PBS (AAV-fGFP) for a total of $1 \mu \mathrm{l}$ injected into each of two DRGs. The rationale for combining the $\alpha 9$ integrin and the fGFP virus was attributable to the inability to localize $\alpha 9$ integrin immunohistochemically because of the lack of reliable antibodies for immunohistochemistry. We confirmed that many DRG neurons express both $\alpha 9$ and GFP (supplemental Fig. S3, available at www.jneurosci.org as supplemental material). Overall, the proportion of DRG neurons transduced with AAV-fGFP was $70-75 \%$, whereas AAV- $\alpha 9$ transduction was $\sim 25-30 \%$. We performed in situ hybridization for GFP and $\alpha 9$ on alternate DRG sections. Because of the large size of DRG neurons, many appeared on neighboring sections. Based on these counts, which are probably an underestimate, $\sim 30 \%$ of GFP-expressing neurons also express $\alpha 9$ integrin after in vivo injection of both viruses. GFP expression in both experimental groups was used in determining axon regeneration, 6 weeks after injury. Numbers of axons in the root proximal to the crush site of the treated DRGs were analyzed, and similar numbers of GFP-expressing axons were found in both groups (Fig. 7C). In the spinal cord DREZ, a known barrier for regenerating axons, there were significantly more axons in the AAV- $\alpha 9$ group (Fig. $7 B, C$ ) than in the AAV-fGFP group (Fig. 7A,C). Some axons in the AAV- $\alpha 9$ group could be seen penetrating further into the cord for short distances (Fig. 7E), and in rare instances GFP-expressing axons were found deep within the spinal cord (Fig. 7D).

After a dorsal root crush injury, a strong upregulation of fulllength TN-C within the spinal cord on the ipsilateral side including throughout the DREZ was detected, with negligible amounts of TN-C expression found on the uninjured side except near the midline of the dorsal funiculus (Fig. 7F). TN-C expression was not detected within the root after crush injury, except at the level of the GFAP-immunoreactive DREZ (Fig. 7G-I). Additionally, TN-C levels were examined in the DRG after injury, to further verify our in vitro results suggesting TN-C expression by dissociated DRGs. In these cases, TN-C was observed within the DRG with a pericellular pattern around the neurons (Fig. 7J-L).

$\alpha 9$ integrin enhances dorsal column axon regrowth into a DC crush lesion

Tenascin-C has been identified as a component of the inhibitory glial scar produced mainly by astrocytes and present after spinal cord injury (for review, see Fawcett and Asher, 1999). Using a similar approach to the dorsal root injury, the C6, C7 DRGs were injected unilaterally with AAV- $\alpha 9$ (with AAV-fGFP) or AAVfGFP after which the dorsal columns were crushed bilaterally at the C4-C5 level. GFP-expressing axons were used in both groups as a means of assessing axon regeneration into the lesion site, 6 weeks after injury. In the control group with AAV-fGFP, GFPexpressing axons were detected in the caudal white matter leading up to the lesion site (Fig. $8 E, F$ ). A few axons were located near the 


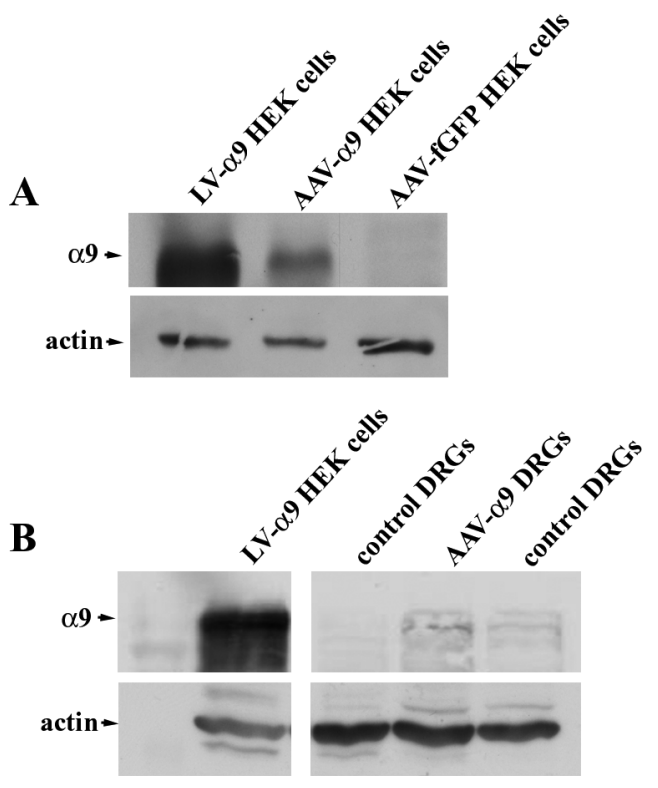

Figure 6. $\quad \alpha 9$ integrin expression after viral transduction in vitro and in vivo. $\boldsymbol{A}$, Western blot analysis of lysates from LV- $\alpha$ 9-IRES-fGFP, AAV- $\alpha 9$, or AAV-fGFP transduced HEK cells. $\boldsymbol{B}$, Western blot analysis of cell lysates of LV- $\alpha$ 9-IRES-fGFP transduced HEK cells, or tissue lysates from AAV- $\alpha 9$ transduced DRGs, or control DRGs (in vivo) examined for the presence of human $\alpha 9$ integrin or actin (loading control).

lesion boundaries and in rare cases were seen to course tangentially around the lesion for short distances (Fig. $8 \mathrm{~J}$ ). After treatment with AAV- $\alpha 9$, axons from the caudal white matter were found entering into the lesion site through areas of GFAP immunoreactivity (Fig. $8 B, C$ ). In some cases, GFP-expressing axons were found within the lesion epicenter (Fig. $8 H, I$ ). Quantification of these axons revealed significantly more axons within the lesion site in the AAV- $\alpha 9$ group than in controls (Fig. $8 \mathrm{~K}$ ). In neither case were axons detected in the rostral white matter beyond the lesion site; however, axons were observed in the adjacent gray matter in a few cases (data not shown). Confirmation of TN-C immunoreactivity revealed expression along the borders of the lesion and within the lesion epicenter (Fig. $8 L$ ). Axons were observed growing along TN-C-immunoreactive fibers in AAV$\alpha 9$-treated groups in some cases (Fig. $8 M$ ).

To test for possible behavioral consequences of $\alpha 9$ expression in DRG neurons, we assessed paw withdrawal latency from a heated surface ("hot-plate test") or from a probe with increasing pressure ("pressure test"). Withdrawal latency values were measured preoperatively on the side of the DRG injection and then compared 5 weeks after injury between groups. The AAV- $\alpha 9$ group had withdrawal latencies near to preoperative levels, whereas the AAV-fGFP group had significantly longer withdrawal latencies than before injury (Fig. 8O). Results from the pressure test did not reveal any significant differences between the AAV- $\alpha 9$ group and the AAV-fGFP group, with both groups showing elevated withdrawal latencies 5 weeks after injury (Fig. $8 N$ ).

\section{Discussion}

The present study investigates the hypothesis that the expression of a tenascin-C binding integrin subunit, $\alpha 9$, could promote the growth of axons on TN-C in vitro, and in the injured CNS in which TN-C is upregulated. The goal of the above experiments was to determine whether expression of $\alpha 9$ integrin could turn an inhibitor of axon regeneration into a growth-promoting molecule.

\section{$\alpha \boldsymbol{9}$ expression promotes neurite outgrowth in vitro}

Our first experiments in PC12 cells demonstrated that $\alpha 9$ integrin expression is a potent promoter of neurite outgrowth on TN-C and that this effect could be abolished with an $\alpha 9 \beta 1$ blocking antibody. $\alpha 9$ integrin-expressing PC12 cells were also able to extend neurites on physiological tenascin-containing substrates such as cortical cryosections and nitrocellulose filter implants from cortical injuries, again prevented by an $\alpha 9 \beta 1$ integrin blocking antibody. We then expressed $\alpha 9$ integrin in primary cultures of dissociated adult rat DRG neurons and observed very similar growth-promoting effects on the same substrates, again inhibited by the blocking antibody.

Previous studies of the role of integrins in axon growth on fibronectin had shown that modifying the extracellular and intracellular domains through chimeric $\alpha$ integrin subunits could produce different axon growth responses on a given substrate. We therefore investigated the effects of manipulating the $\alpha 9$ extracellular and intracellular domains. Interestingly, our data demonstrate that neurite outgrowth on TN-C occurs independently of the cytoplasmic domain of $\alpha 9$ integrin but is dependent on the extracellular domain. Previous studies examining $\alpha 4 \beta 1$ integrin binding and neurite outgrowth on fibronectin have shown that the cytoplasmic domain is imperative for neurite outgrowth (Vogelezang et al., 2001), with a direct association existing between the cytoplasmic domain of $\alpha 4 \beta 1$ integrin and the cytoskeletal adaptor protein paxillin (Vogelezang et al., 2001). With regard to $\alpha 9 \beta 1$ integrin signaling, experiments in SW480 cells have shown that paxillin and FAK (focal adhesion kinase) become phosphorylated subsequent to ligand binding, specifically after the association of $\alpha 9 \beta 1$ integrin to the fn 3 binding domain of TN-C (Yokosaki et al., 1996). Our data, in which we have substituted various intracellular domains and deleted the $\alpha 9$ intracellular domain without effects on neurite outgrowth, suggest that in axons the $\alpha 9$ extracellular domain is necessary for ligand specificity, whereas intracellular signaling is most likely mediated through the $\beta 1$ integrin cytoplasmic domain or possibly by association of another molecule in cis with the $\alpha 9$.

An unexpected result, observed in both DRG neurons and PC1 2 cells transfected with $\alpha 9$, was that they demonstrated neurite outgrowth on uncoated tissue culture plastic, suggesting that the cultured cells deposit an $\alpha 9$ ligand on the surrounding plastic. $\alpha 9$ integrin can bind to TN-C, osteopontin, fibronectin, and VCAM-1 (Smith et al., 1996; Yokosaki et al., 1996; Taooka et al., 1999; Liao et al., 2002). Our results indicate that $\alpha 9$ integrin binding to TN-C produced by PC12 cells and DRG neurons is responsible for enabling neurite outgrowth on plastic. Outgrowth on plastic, TN-C, and physiological substrates is $\alpha 9$ dependent, being greatly reduced by an $\alpha 9 \beta 1$ blocking antibody. We therefore evaluated proteins within PC12 cell lysates and conditioned media of PC12 cells. This showed that they produce high levels of TN-C, but osteopontin was not detectable. Additional examination indicated TN-C immunoreactivity in both the cell bodies and the processes of PC12 cells and DRGs, with TN-C immunoreactivity observed deposited on the tissue culture surface adjacent to cultured DRG neurons. The secreted ligand could not be fibronectin because cells transfected with the fibronectin-binding integrins $\alpha 4$ and $\alpha 5$ showed no growth on plastic, and similarly $\alpha 4$ is a VCAM binding integrin yet did not promote outgrowth on plastic. These data suggest that an autocrine signaling loop is occurring between secreted TN-C and $\alpha 9$ integrin in addition to binding exogenous $\mathrm{TN}-\mathrm{C}$ on the culture surface. Tenascin-C knockdown showed that neurite outgrowth from $\alpha 9$ integrin-expressing cells on plastic was reduced. 

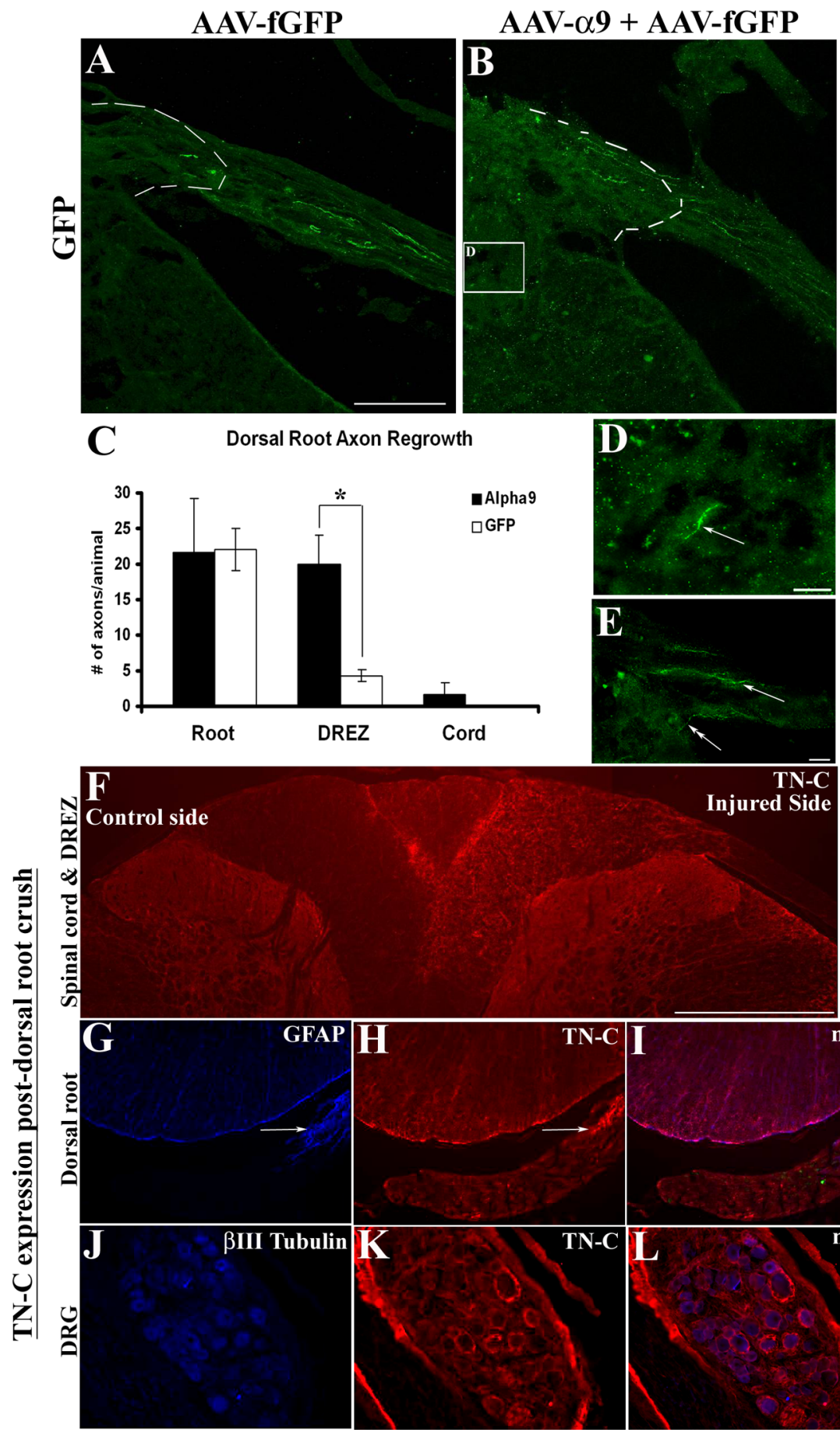
with attached spinal cord, showing GFP-expressing axons 6 weeks after treatment transduced with AAV-fGFP alone $(\boldsymbol{A})$ or with AAV- $\alpha 9$ integrin plus AAV-fGFP ( $\boldsymbol{B})$. The DREZ boundary is approximated with a dashed line. C, Quantification of GFP-expressing axons in the root, proximal to the crush, in the DREZ, and in the spinal cord. The asterisk $\left.{ }^{*}\right)$ indicates significantly $(p<0.05)$ more axons were found in the DREZ in the $\alpha 9$ integrin group. High-magnification image of a GFP-labeled axon ( $\boldsymbol{D}$, arrow) located in the spinal cord after $\alpha 9$ integrin treatment from a region approximated by the box in $\boldsymbol{B}$. High-magnification image of a DREZ after $\alpha 9$ integrin treatment showing a GFP-labeled axon entering the cord from the entry zone along with other axons within the DREZ ( $\boldsymbol{E}$, arrows). TN-C immunoreactivity is shown 3 weeks after dorsal root injury in the spinal cord $(\boldsymbol{F})$, in the injured dorsal root $(\mathbf{G}-\boldsymbol{I})$, and in the DRG (J-L). Error bars indicate SEM. Scale bars: $\boldsymbol{A}, 50 \mu \mathrm{m}$; (in $\boldsymbol{D}) \boldsymbol{D}, \boldsymbol{E}, 10 \mu \mathrm{m} ; \boldsymbol{F}, 500 \mu \mathrm{m}$; (in $\boldsymbol{L}) \mathbf{G}-\boldsymbol{L}, 100 \mu \mathrm{m}$.

\section{Expression of $\alpha 9$ integrin in DRG neurons}

In the mature CNS, $\alpha 9$ expression is seen only in the choroid plexus (Wang et al., 1995). We observed $\alpha 9$ expression in newborn DRG neurons, but not in adults. Some integrins are upregulated after axotomies affecting DRGs (Werner et al., 2000; Vo-
TN-C

gelezang et al., 2001), but we did not see any reexpression of $\alpha 9$, so upregulation of developmentally expressed integrins is clearly not a universal phenomenon after axotomy.

\section{$\alpha 9$ expression enhances axon regeneration in vivo}

Because our in vitro experiments had demonstrated greatly enhanced axon regeneration from adult DRG neurons, we investigated whether $\alpha 9$ expression would stimulate axon regeneration in the same neurons in vivo. We used two lesion models, regeneration of axons into the DREZ of the spinal cord after dorsal rhizotomy and axonal regrowth into a dorsal column injury site after a spinal cord lesion. In both cases, these lesions lead to upregulation of TN-C in the region of the axotomy. In both models, we saw an increase in axon regeneration relative to controls, with evidence of functional effects in the spinal cord injury model, but the extent of axon regeneration was considerably less extensive than we observed in transfected neurons in vitro.

A concern with any treatment that increases sensory axon regeneration is whether there is an increase in pain sensation. Evaluating behavioral changes after dorsal column crush injury and overexpression of $\alpha 9$ integrin, we found a return toward the preoperative withdrawal latency in response to heat stimulation in the treated animals, whereas the withdrawal threshold remained high in the GFP control group. This result suggests that pain fibers carried in the anterolateral tract had regrown as a result of overexpression of $\alpha 9$ integrin, but had not made aberrant connections that might lead to hyperalgesia. With regard to the pressure test, however, withdrawal latencies remained elevated 5 weeks after injury in both the experimental and control groups. Although significantly more fibers grew into the lesion site in $\alpha 9$ integrin-treated animals, growth was not sufficient to reform connections to transmit mechanosensory information.

An interesting observation in this study was a disparity between the substantial neurite outgrowth promoted by $\alpha 9$ expression in vitro and the more modest axon regeneration that we observed in vivo. Only a few transduced axons extended past the DREZ after dorsal rhizotomy, and no axons were detected past the injury site after a dorsal column crush lesion. We do not believe that we failed to detect regenerating axons. Our quantitation was based on coexpression of GFP and $\alpha 9$, which was necessary because there are no suitable antibodies available that label $\alpha 9$ integrin immunohistochemically. However, the farnesylated GFP 

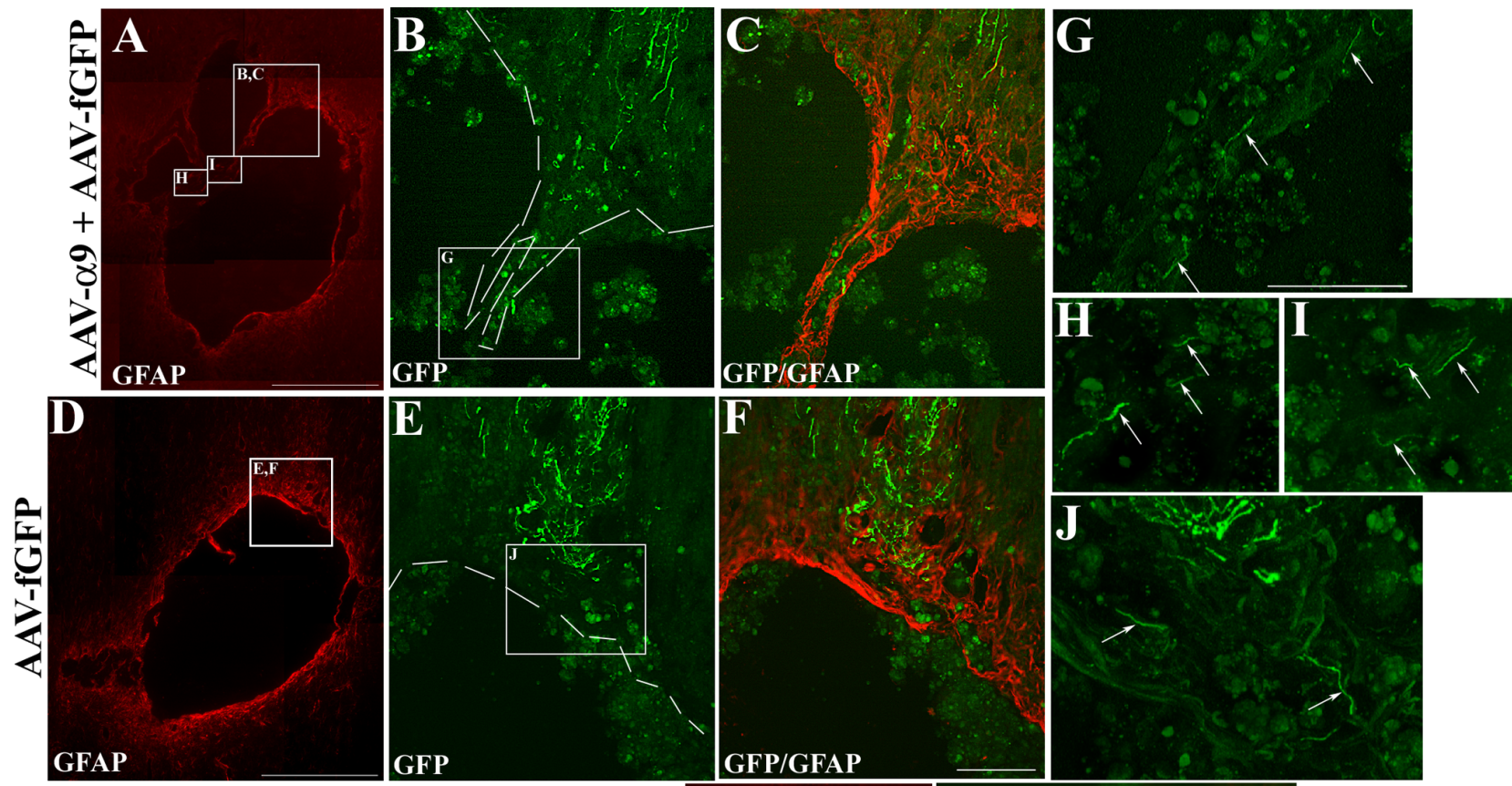

K Dorsal Column Axon Regrowth into Lesion Cavity
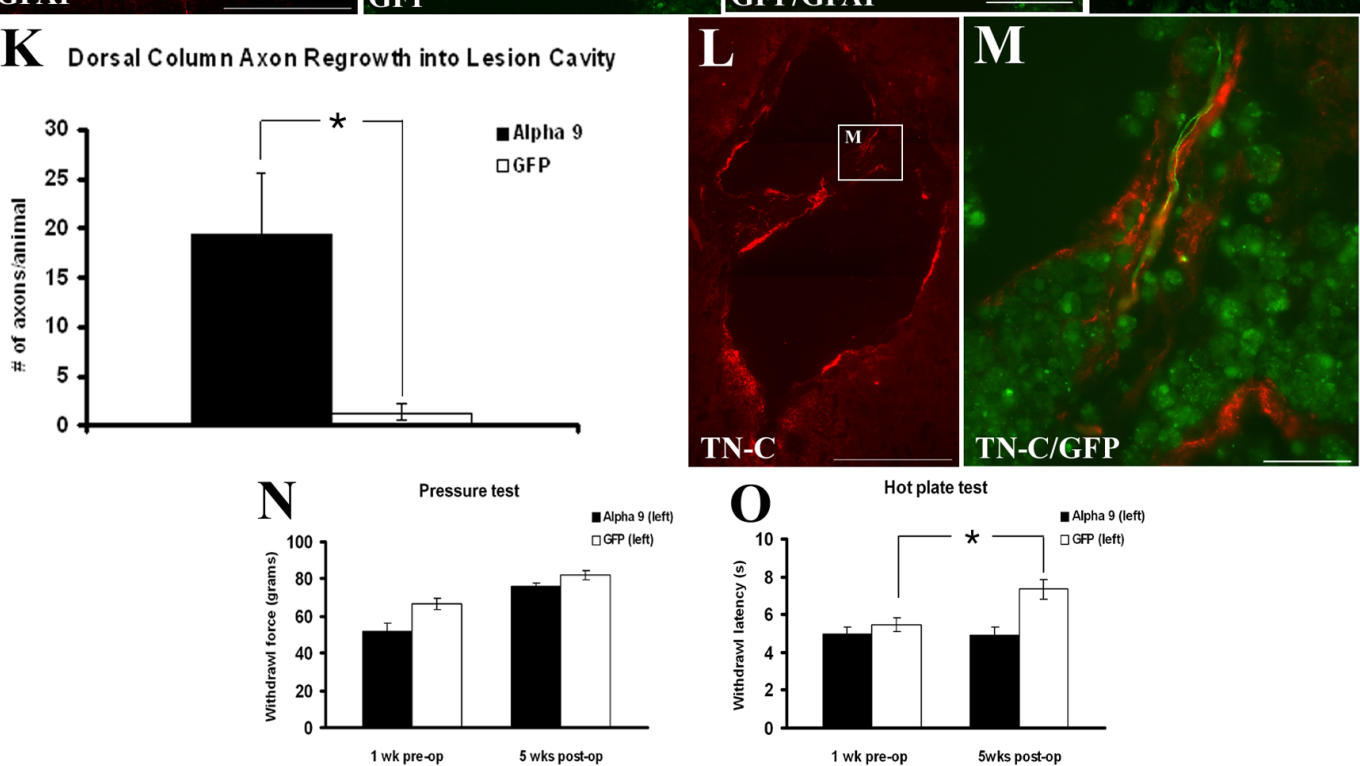

Figure 8. $\alpha 9$ integrin enhances sensory axon growth into a dorsal column crush lesion. Shown are longitudinal sections through the dorsal column-injured spinal cord 6 weeks after treatment with AAV- $\alpha 9$ integrin plus AAV-fGFP $(\boldsymbol{A}-\boldsymbol{C}, \boldsymbol{G}-\boldsymbol{I})$, or AAV-fGFP alone $(\boldsymbol{D}-\boldsymbol{F}, \boldsymbol{J})$. $\boldsymbol{K}$, Quantification of GFP-labeled axons within the lesion boundaries in the $\alpha 9$ integrin-treated and the control-treated groups. The asterisk (*) indicates significantly ( $p<0.05$ ) more axons were present within the lesion site in the $\alpha 9$ group. $L, M$, Longitudinal section through the lesion site after $\alpha 9$ integrintreatment immunostained for TN-C, showing a GFP-labeled axon growing along a TN-C-immunopositive fiber. $\boldsymbol{N}, \mathbf{O}$, Quantification of behavioral data for the pressure test $(\boldsymbol{N})$ and the hot-plate test (0), before injury and at 5 weeks after injury. Error bars indicate SEM. Scale bars: $\boldsymbol{A}, \boldsymbol{D}, \mathbf{L}, 500 \mu \mathrm{m}$; (in $\boldsymbol{F}) \boldsymbol{B}, \boldsymbol{C}, \boldsymbol{E}, \boldsymbol{F}, 100 \mu \mathrm{m}$; (in $\mathbf{G}) \mathbf{G}-\boldsymbol{J}, \boldsymbol{M}, 100 \mu \mathrm{m}$.

that we expressed completely labels sensory axons in unlesioned animals and should therefore label small regenerating axons. It is possible that there was a "honeypot" effect, with regenerating axons preferring an area of high TN-C expression, and not growing on into less damaged parts of the CNS that did not have high levels of TN-C expression. However, as shown in Figure 7, TN-C upregulation was widespread. More probable is that $\alpha 9$ expressing axons in vivo are subject to influences that are not present in vitro. NogoA has been shown to affect integrin activation (Hu and Strittmatter, 2008), and our unpublished results show a similar effect of chondroitin sulfate proteoglycans, so it is possible that $\alpha 9$ was present in cut axons but much of it was inactivated. A second issue may be integrin trafficking in cut CNS axons. Little is known about the mechanisms of integrin traffick- ing in regenerating axons, but in principle the process is subject to many influences from the extracellular environment (Jones et al., 2006). Current studies in our laboratory are investigating integrin trafficking and activation after overexpression in both PC12 cells and DRG neurons with a view to developing methods to optimize the effectiveness of integrin expression as a treatment for enhancing axon regeneration in the damaged CNS.

Our results establish that $\alpha 9 \beta 1$ integrin enhances neurite outgrowth both in vitro and in vivo on TN-C-rich substrates. In our in vivo paradigms, we observed promising initial results based on a gene therapy strategy, but additional manipulation of integrin activation and trafficking will be needed to make this strategy sufficiently effective for therapeutic use. TN-C is abundant in the injured nervous system and the presence of the correct receptor 
on neurons is a necessary step to promoting growth through sites of injury. It is probable that manipulations of axonal integrins could have an additive effect to strategies that modify the environment of the damaged CNS, such as chondroitinase treatment, NogoA manipulation or cell transplantation at the lesion site.

\section{References}

Baker KA, Hagg T (2007) Developmental and injury-induced expression of alphalbetal and alpha6betal integrins in the rat spinal cord. Brain Res 1130:54-66.

Bartsch U (1996) The extracellular matrix molecule tenascin-C: expression in vivo and functional characterization in vitro. Prog Neurobiol 49:145-168.

Carulli D, Rhodes KE, Brown DJ, Bonnert TP, Pollack SJ, Oliver K, Strata P, Fawcett JW (2006) Composition of perineuronal nets in the adult rat cerebellum and the cellular origin of their components. J Comp Neurol 494:559-577.

Condic ML (2001) Adult neuronal regeneration induced by transgenic integrin expression. J Neurosci 21:4782-4788.

Condic ML, Snow DM, Letourneau PC (1999) Embryonic neurons adapt to the inhibitory proteoglycan aggrecan by increasing integrin expression. J Neurosci 19:10036-10043.

Faissner A, Kruse J (1990) J1/tenascin is a repulsive substrate for central nervous system neurons. Neuron 5:627-637.

Fawcett JW, Asher RA (1999) The glial scar and CNS repair. Brain Res Bull 49:377-391.

Gardiner NJ, Fernyhough P, Tomlinson DR, Mayer U, von der Mark H, Streuli $\mathrm{CH}$ (2005) Alpha7 integrin mediates neurite outgrowth of distinct populations of adult sensory neurons. Mol Cell Neurosci 28:229-240.

Gardiner NJ, Moffatt S, Fernyhough P, Humphries MJ, Streuli CH, Tomlinson DR (2007) Preconditioning injury-induced neurite outgrowth of adult rat sensory neurons on fibronectin is mediated by mobilisation of axonal alpha5 integrin. Mol Cell Neurosci 35:249-260.

Golding JP, Bird C, McMahon S, Cohen J (1999) Behaviour of DRG sensory neurites at the intact and injured adult rat dorsal root entry zone: postnatal neurites become paralysed, whilst injury improves the growth of embryonic neurites. Glia 26:309-323.

Hu F, Strittmatter SM (2008) The N-terminal domain of Nogo-A inhibits cell adhesion and axonal outgrowth by an integrin-specific mechanism. J Neurosci 28:1262-1269.

Joester A, Faissner A (2001) The structure and function of tenascins in the nervous system. Matrix Biol 20:13-22.

Jones LS (1996) Integrins: possible functions in the adult CNS. Trends Neurosci 19:68-72.

Jones MC, Caswell PT, Norman JC (2006) Endocytic recycling pathways: emerging regulators of cell migration. Curr Opin Cell Biol 18:549-557.

Lein PJ, Higgins D, Turner DC, Flier LA, Terranova VP (1991) The NC1 domain of type IV collagen promotes axonal growth in sympathetic neurons through interaction with the alpha 1 beta 1 integrin. J Cell Biol 113:417-428.

Liao YF, Gotwals PJ, Koteliansky VE, Sheppard D, Van De Water L (2002) The EIIIA segment of fibronectin is a ligand for integrins alpha 9beta 1 and alpha 4beta 1 providing a novel mechanism for regulating cell adhesion by alternative splicing. J Biol Chem 277:14467-14474.

McKeon RJ, Schreiber RC, Rudge JS, Silver J (1991) Reduction of neurite outgrowth in a model of glial scarring following CNS injury is correlated with the expression of inhibitory molecules on reactive astrocytes. J Neurosci 11:3398-3411.

McKeon RJ, Höke A, Silver J (1995) Injury-induced proteoglycans inhibit the potential for laminin-mediated axon growth on astrocytic scars. Exp Neurol 136:32-43.

Meiners S, Mercado ML, Nur-e-Kamal MS, Geller HM (1999) Tenascin-C contains domains that independently regulate neurite outgrowth and neurite guidance. J Neurosci 19:8443-8453.

Naldini L, Blömer U, Gallay P, Ory D, Mulligan R, Gage FH, Verma IM, Trono D (1996) In vivo gene delivery and stable transduction of nondividing cells by a lentiviral vector. Science 272:263-267.

Neugebauer KM, Emmett CJ, Venstrom KA, Reichardt LF (1991) Vitronectin and thrombospondin promote retinal neurite outgrowth: developmental regulation and role of integrins. Neuron 6:345-358.

Pindzola RR, Doller C, Silver J (1993) Putative inhibitory extracellular matrix molecules at the dorsal root entry zone of the spinal cord during development and after root and sciatic nerve lesions. Dev Biol 156:34-48.
Pinkstaff JK, Detterich J, Lynch G, Gall C (1999) Integrin subunit gene expression is regionally differentiated in adult brain. J Neurosci 19:1541-1556.

Rigato F, Garwood J, Calco V, Heck N, Faivre-Sarrailh C, Faissner A (2002) Tenascin-C promotes neurite outgrowth of embryonic hippocampal neurons through the alternatively spliced fibronectin type III BD domains via activation of the cell adhesion molecule F3/contactin. J Neurosci 22:6596-6609.

Ruitenberg MJ, Plant GW, Christensen CL, Blits B, Niclou SP, Harvey AR, Boer GJ, Verhaagen J (2002) Viral vector-mediated gene expression in olfactory ensheathing glia implants in the lesioned rat spinal cord. Gene Ther 9:135-146.

Smith LL, Cheung HK, Ling LE, Chen J, Sheppard D, Pytela R, Giachelli CM (1996) Osteopontin N-terminal domain contains a cryptic adhesive sequence recognized by alpha9betal integrin. J Biol Chem 271:28485-28491.

Staniszewska I, Sariyer IK, Lecht S, Brown MC, Walsh EM, Tuszynski GP, Safak M, Lazarovici P, Marcinkiewicz C (2008) Integrin alpha9 beta1 is a receptor for nerve growth factor and other neurotrophins. J Cell Sci 121:504-513.

Tang X, Davies JE, Davies SJ (2003) Changes in distribution, cell associations, and protein expression levels of NG2, neurocan, phosphacan, brevican, versican V2, and tenascin-C during acute to chronic maturation of spinal cord scar tissue. J Neurosci Res 71:427-444.

Taooka Y, Chen J, Yednock T, Sheppard D (1999) The integrin alpha9betal mediates adhesion to activated endothelial cells and transendothelial neutrophil migration through interaction with vascular cell adhesion molecule-1. J Cell Biol 145:413-420.

Tomaselli KJ, Doherty P, Emmett CJ, Damsky CH, Walsh FS, Reichardt LF (1993) Expression of $\beta 1$ integrins in sensory neurons of the dorsal root ganglion and their functions in neurite outgrowth on two laminin isoforms. J Neurosci 13:4880-4888.

Vlahakis NE, Young BA, Atakilit A, Sheppard D (2005) The lymphangiogenic vascular endothelial growth factors VEGF-C and -D are ligands for the integrin alpha9beta1. J Biol Chem 280:4544-4552.

Vlahakis NE, Young BA, Atakilit A, Hawkridge AE, Issaka RB, Boudreau N, Sheppard D (2007) Integrin alpha9betal directly binds to vascular endothelial growth factor (VEGF)-A and contributes to VEGF-A-induced angiogenesis. J Biol Chem 282:15187-15196.

Vogelezang M, Forster UB, Han J, Ginsberg MH, ffrench-Constant C (2007) Neurite outgrowth on a fibronectin isoform expressed during peripheral nerve regeneration is mediated by the interaction of paxillin with alpha4betal integrins. BMC Neurosci 8:44.

Vogelezang MG, Liu Z, Relvas JB, Raivich G, Scherer SS, ffrench-Constant C (2001) $\alpha 4$ integrin is expressed during peripheral nerve regeneration and enhances neurite outgrowth. J Neurosci 21:6732-6744.

Wang A, Patrone L, McDonald JA, Sheppard D (1995) Expression of the integrin subunit alpha 9 in the murine embryo. Dev Dyn 204:421-431.

Werner A, Willem M, Jones LL, Kreutzberg GW, Mayer U, Raivich G (2000) Impaired axonal regeneration in $\alpha 7$ integrin-deficient mice. J Neurosci 20:1822-1830.

Xiao X, Li J, Samulski RJ (1998) Production of high-titer recombinant adeno-associated virus vectors in the absence of helper adenovirus. JVirol 72:2224-2232.

Yokosaki Y, Palmer EL, Prieto AL, Crossin KL, Bourdon MA, Pytela R, Sheppard D (1994) The integrin alpha 9 beta 1 mediates cell attachment to a non-RGD site in the third fibronectin type III repeat of tenascin. J Biol Chem 269:26691-26696.

Yokosaki Y, Monis H, Chen J, Sheppard D (1996) Differential effects of the integrins alpha9beta1, alphavbeta3, and alphavbeta6 on cell proliferative responses to tenascin. Roles of the beta subunit extracellular and cytoplasmic domains. J Biol Chem 271:24144-24150.

Yokosaki Y, Matsuura N, Higashiyama S, Murakami I, Obara M, Yamakido M, Shigeto N, Chen J, Sheppard D (1998) Identification of the ligand binding site for the integrin alpha9 betal in the third fibronectin type III repeat of tenascin-C. J Biol Chem 273:11423-11428.

Yokosaki Y, Matsuura N, Sasaki T, Murakami I, Schneider H, Higashiyama S, Saitoh Y, Yamakido M, Taooka Y, Sheppard D (1999) The integrin alpha(9)beta(1) binds to a novel recognition sequence (SVVYGLR) in the thrombin-cleaved amino-terminal fragment of osteopontin. J Biol Chem 274:36328-36334.

Zhang Y, Winterbottom JK, Schachner M, Lieberman AR, Anderson PN (1997) Tenascin-C expression and axonal sprouting following injury to the spinal dorsal columns in the adult rat. J Neurosci Res 49:433-450. 